\title{
Exercise restores chloride homeostasis and decreases spasticity through the BDNF-KCC2 pathway after chronic SCI
}

\author{
Henrike Schulze $^{1}$, Samantha Choyke ${ }^{1}$, Michael Klaszky ${ }^{1}$, Marie-Pascale Côté Ph.D. ${ }^{1}$ \\ ${ }^{1}$ Department of Neurobiology and Anatomy, Drexel University College of Medicine, \\ Philadelphia, PA 19129
}

\section{$\underline{\text { Author information }}$}

Marie-Pascale Côté, Ph.D. (corresponding author)

Assistant Professor

Drexel University College of Medicine

Department of Neurobiology and Anatomy

Philadelphia, PA 19129

Phone: 215-991-8598

Fax: 215-843-9082

Email: mc849@drexel.edu

Keywords: spinal cord injury, rehabilitation, chloride homeostasis, neuroplasticity, KCC2

\begin{abstract}
Abbreviations:
$\mathrm{BDNF}=$ brain-derived neurotrophic factor; DMSO = Dimethyl sulfoxide; FDD = Frequencydependent depression; PMSF = phenyl-methyl sulphonyl-fluoride; SCI = Spinal Cord Injury; TrkB $=$ tyrosine receptor kinase $\mathrm{B}$.
\end{abstract}




\begin{abstract}
Activity-based therapies are routinely integrated in rehabilitation programs to induce repetitive activation of the neuromuscular system and facilitate functional recovery after spinal cord injury (SCI). Among the beneficial effects of physical therapy is a reduction of hyperreflexia and spasticity in SCI individuals, but the precise mechanism by which exercise regulates spinal networks and facilitate recovery remains elusive. Spasticity is a debilitating condition that affects $\sim 75 \%$ of the SCI population and interferes with residual motor function. Current pharmacological treatments not only have serious side effects but also actively depress spinal excitability and interferes with motor recovery. Understanding how activity-based therapies contribute to decrease spasticity will help identify critical pharmacological targets and optimize rehabilitation programs.
\end{abstract}

$\mathrm{KCC} 2$, a neuron-specific $\mathrm{Cl}^{-}$extruder, is critical to the maintenance of $\left[\mathrm{Cl}^{-}\right]_{\mathrm{i}}$ and its downregulation after SCI leads to a shift in chloride homeostasis that contributes to develop spasticity. We have shown in earlier studies that not only exercise promotes reflex modulation but also restores KCC2 expression in motoneurons. KCC2 is dynamically modulated by several signaling pathways, the most prevalent being BDNF-TrkB. Interestingly, activity-dependent processes triggered by exercise include an increase in the expression of BDNF in the lumbar spinal cord. However, whether the increase in KCC2 contributes to functional recovery and rely on BDNF activity have not been established. Our objective was to determine 1) whether the activity-dependent upregulation of KCC2 contributes to decrease spasticity after SCI; 2) if BDNF regulates KCC2 expression in an activity-dependent manner.

Using a model of complete SCI, we investigated this possible causal effect by intrathecally delivering VU0240551, a specific KCC2 blocker, or TrkB-IgG, a BDNF scavenger. Drugs were specifically delivered during the daily rehabilitation sessions to transiently prevent KCC2/BDNF activity. We provide evidence that the beneficial effect of exercise on functional recovery relies on a BDNF-dependent increase in $\mathrm{KCC} 2$ expression on motoneurons and the restoration of endogenous inhibition to a mature state. We identify, for the first time, that the increase in KCC2 activity with activity-based therapies functionally contributes to H-reflex recovery and critically depends on BDNF activity. This provides a new perspective on our understanding of how exercise 
impact hyperreflexia by identifying the biological basis of recovery of function. Acting directly on chloride homeostasis through BDNF to restore endogenous inhibition rather than actively depress excitability can diminish the reduction in motor output associated with the current pharmacological management of SCI and improve the outcome of rehabilitation programs. 


\section{Introduction}

Activity-based therapies promote sensorimotor functional recovery after SCI and are routinely integrated in rehabilitation programs in the clinic. Amongst its beneficial effects is a decrease in spasticity that reduces incapacitating symptoms and significantly improve the quality of life of SCI individuals (Dietz, 2001; Petropoulou et al., 2007). Spasticity is a debilitating condition affecting up to $75 \%$ of SCI individuals, with most SCI individuals experiencing episodes one year after injury (Maynard et al., 1990; Skold et al., 1999; Holtz et al., 2017). Currently available anti-spastic drugs have serious side effects including sedation, dizziness and a deep, long-lasting depression of spinal excitability that significantly reduces muscle activity and interferes with motor recovery (Dario and Tomei, 2004; Adams and Hicks, 2005; Elbasiouny et al., 2010; Angeli et al., 2012). There is therefore a critical need to identify new targets to diminish spasticity in SCI individuals.

Evidence-based clinical practice highlights the beneficial effect of a rehabilitation program on spastic symptoms which suggests the involvement of a potent activity-dependent mechanism. To date, the most compelling finding indicates a critical role for BDNF in promoting activitydependent plasticity. BDNF is released in an activity-dependent manner ( $\mathrm{Lu}, 2003)$ and its contribution to functional plasticity in the healthy and injured spinal cord has been extensively studied (reviewed in Boyce and Mendell, 2014a,b). Exercise increases BDNF serum levels in SCI individuals (Leech and Hornby, 2017). While the consequences of this activity-dependent increase remains to be determined in humans, experiments performed in animal models of chronic SCI suggest that it is associated with an enhanced response of spinal motor pools to descending drive, normalization of motoneuronal electrophysiological properties, improvement in reflex modulation and locomotor recovery, and reduction in allodynia (Hutchinson et al., 2004; Beaumont et al., 2008; Ying et al., 2008; Côté et al., 2011; Skup et al., 2014).

Interestingly, BDNF acts as a regulator of the $\mathrm{K}^{+}-\mathrm{Cl}^{-}$cotransporter $\mathrm{KCC} 2$ in various disease models including neuropathic pain and hyperalgesia (Rivera et al., 2002; 2004; Coull et al., 2005; Miletic and Miletic, 2008; Ferrini et al., 2013). After chronic SCI, KCC2 is downregulated in spinal neurons causing an increase in intracellular chloride concentration $\left(\left[\mathrm{Cl}^{-}\right]_{\mathrm{i}}\right)$. Consequently, GABA-mediated responses become less hyperpolarizing and lead to increased spinal reflex excitability and a significant reduction in postsynaptic inhibition (Lu et al., 2008; Boulenguez et 
al., 2010; Gackiere and Vinay, 2015). Exercise increases both BDNF and KCC2 levels in the lumbar spinal cord after a chronic SCI in animals that display less spasticity and better reflex modulation (Côté et al., 2011; 2014). While it is generally accepted that activity-based therapies increase KCC2 expression in lumbar motoneurons (Côté et al., 2014; Chopek et al., 2015; Tashiro et al., 2015), the potential contribution to functional recovery remains to be determined.

Mechanisms of activity-dependent regulation of $\mathrm{KCC} 2$ and subsequent shift in $\mathrm{E}_{\mathrm{GABA}}$ include TrkB activation by BDNF (Aguado et al., 2003; Ludwig et al., 2011; Kaila et al., 2014a,b). In the hippocampus, the regulation of $\mathrm{KCC} 2$ following neonatal status epilepticus is dependent on BDNF and accompanied by a significant increase in KCC2 expression on neuronal surface, enhancement of neuronal $\mathrm{Cl}^{-}$extrusion, and hyperpolarized $\mathrm{E}_{\mathrm{GABA}}$ (Khirug et al., 2010; Puskarjov et al., 2015). We therefore hypothesized that the beneficial effect of rehabilitation on the modulation of spinal reflexes relies on a BDNF-dependent increase in $\mathrm{KCC} 2$ expression in motoneurons and the restoration of endogenous inhibition.

Adult rats received a spinal transection (T12), and were exercised on motorized bikes for 4 weeks. During this exercise period, animals were treated with the specific KCC2 blocker VU0240551 or TrkB-IgG to chelate BDNF. During a terminal experiment, H-reflexes were recorded and analyzed as a measure of hyperreflexia and spasticity. Our data illustrate that preventing $\mathrm{KCC} 2$ activity during exercise impedes reflex recovery after $\mathrm{SCI}$ and that the upregulation of $\mathrm{KCC} 2$ expression triggered by exercise requires BDNF to restore reflex modulation. These results strongly suggest the presence of activity-dependent mechanisms involved in the regulation of chloride cotransporters in the spinal cord and demonstrate their involvement in functional recovery after SCI. This further lends support to chloride cotransporters as effective targets to improve motor recovery after SCI. 


\section{Materials and methods}

\section{Experimental design}

In a SCI rat model of complete thoracic transection injury (T12), we investigated the role of $\mathrm{KCC} 2$ in motor recovery after a chronic SCI and its dependence on the activity-dependent regulation of BDNF in the lumbar spinal cord by using VU0240551, a selective inhibitor of KCC2 or chelating the endogenously released BDNF with the fusion protein TrkB-IgG. Both were delivered intrathecally during the rehabilitation program. Rats were randomly assigned to one of the following groups: 1) intact ( $\mathrm{n}=11)$; 2) SCI sedentary control rats receiving the vehicle ( $\mathrm{SCI}, \mathrm{n}=14)$; 3) SCI receiving the KCC2 blocker VU0240551 (SCI+VU0240551, n=8); 4) SCI receiving the BDNF scavenger TrkB-IgG (SCI+TrkB-IgG, n=9), 5) SCI bike-trained receiving the vehicle (SCI+Ex, n=14); 6) SCI bike-trained receiving VU0240551 (SCI+Ex+VU0240551, n=14); 7) SCI-biked trained receiving TrkB-IgG (SCI+Ex+TrkB-IgG, n=11). Hyperreflexia was assessed 4 weeks after SCI and the spinal cord tissue harvested for immunohistochemistry or western blot analysis.

All procedures complied with ARRIVE, were conducted in compliance with the guidelines of the National Institutes of Health for the care and use of laboratory animals and approved by Drexel University Institutional Animal Care and Use Committee.

\section{Surgical procedures and postoperative care}

Adult female Sprague-Dawley rats $(\mathrm{n}=106,225-250 \mathrm{~g}$, Charles Rivers Laboratories) were used in this study and the timeline for procedures illustrated in Fig. 1A. All rats were housed by pairs in cages in a $12 \mathrm{~h}$ light-dark cycle and controlled room temperature with ad libitum access to food. All animals but the intact group underwent a complete spinal cord transection at T12 under aseptic conditions as described previously (Côté et al., 2014). Briefly, rats were anaesthetized with isoflurane (1-4\%) and their back shaved, cleansed and disinfected. Body temperature was maintained $\sim 37^{\circ} \mathrm{C}$ throughout the surgical procedure and post-surgical recovery. A laminectomy (T10-11) was performed, the dura slit open and a $2 \mathrm{~mm}$ cavity created by aspiration. A second laminectomy was also performed (L2) and the proximal end of an intrathecal catheter (Alzet ${ }^{\circledR}$, Durect Corporation) threaded rostrally in the subdural space over a $\sim 10 \mathrm{~mm}$ distance. The catheter 
was secured and glued onto a dry clean transverse process and the distal end coupled to a programmable microinfusion pump (iPrecio ${ }^{\odot}$, Durect Corporation) (Tan et al., 2011). The pump reservoir was filled with saline and the drug delivery program activated. Back muscles were sutured in layers leaving the distal end of the catheter exiting between 2 sutures. The pump was positioned subcutaneously just below the shoulder blades and sutured to back muscles. The remaining portion of tubing was coiled for stress relief and the skin closed with staples. The completeness of the lesion was recognized by the retraction of the rostral and caudal portions of the spinal cord and inspecting the ventral floor of the spinal canal during the surgery as well as confirmed post-mortem. The animals were given saline $(5 \mathrm{~mL} /$ day s.c. for 3 days) to avoid dehydration, prophylactic cefazolin $(160 \mathrm{mg} / \mathrm{kg} /$ day s.c. for 7 days $)$ and slow release buprenorphine $(0.05 \mathrm{mg} / \mathrm{kg}$, s.c. $)$ as an analgesic for pain control. Bladders were expressed manually twice a day until the end of the study.

\section{Drug delivery}

KCC2 activity was blocked using VU0240551 (Sigma-Aldrich), VU0240551 was resuspended in DMSO as a $50 \mathrm{mM}$ stock solution, and later diluted in saline to the appropriate concentration. Recombinant human TrkB Fc chimera protein (TrkB-IgG; R\&D company), used to chelate the endogenously released BDNF, was diluted in PBS. Parameters for drug delivery (dose, volume, time to reach maximal effect at the time of training) are consistent with previous reports (GomezPinilla et al., 2007; Austin and Delpire, 2011; Tashiro et al., 2015). The specific delivery protocol and dosage are described in Fig. 1.

\section{Rehabilitation program}

Beginning on day 5, exercised groups received a 60 minutes bicycling session. Animals were seated in a support harness with the hindlimbs hanging while their feet were secured to pedals with surgical tape. The custom-built motor-driven apparatus moves the hindlimbs through a complete range of motion during pedal rotation at a rate of $45 \mathrm{rpm}$ (Houle et al., 1999; Côté et al., 2014). The rehabilitation program took place 5 days a week until completion of the study. 


\section{Electrophysiological recordings and analysis}

H-reflex recordings were performed 4 weeks post-SCI as described previously (Côté et al., 2011; 2014). Rats were anaesthetized with ketamine $(60 \mathrm{mg} / \mathrm{kg})$ and xylazine $(10 \mathrm{mg} / \mathrm{kg})$ administered intraperitoneally. The tibial nerve was dissected free and mounted on a bipolar hook electrode for stimulation. Skin flaps were used to form a pool of mineral oil to prevent desiccation of the nerve. Bipolar wire electrodes (Cooner Wire) were inserted into the interosseus muscles for EMG recordings and the ground electrode inserted into the skin of the back. H-reflexes were evoked via an isolated pulse stimulator (A-M Systems) that delivered single bipolar pulses (100 $\mu \mathrm{sec})$ to the tibial nerve, and $\mathrm{H}$ - and $\mathrm{M}$-waves were recorded in the interosseus muscle in response to a range of increasing stimulus intensities. The intensity that elicited the maximal H-reflex amplitude (below the activation threshold for group Ib-II afferents 1.2-1.4 MT) was then used to determine the properties of the M-wave and H-reflex as well as to evoke frequency-dependent depression (FDD). FDD was estimated using three series of 20 consecutive stimulations delivered at $0.3,5$, and $10 \mathrm{~Hz}$. The experiment was first completed on the left leg, and the protocol then performed on the right leg.

EMG recordings were amplified (A-M system) and bandpass filtered $(10-5 \mathrm{kHz})$, and the signal digitized $(10 \mathrm{kHz})$ using a 1401 interface (Cambridge Electronic Design, CED) and fed to a computer running Signal 5 software (CED). Properties of the M-wave and H-reflex ( $n=8-13$ animals/group, Table 1) are presented as mean \pm SEM. For the analysis of the FDD, the first five responses to a train of stimulation were discarded to allow reflex stabilization. The 15 remaining responses were then averaged. Peak-to-peak amplitude of the $\mathrm{M}$ and $\mathrm{H}$ responses were measured and the H-reflex amplitude normalized to $\mathrm{M}_{\max }$. The change in H-reflex peak-to-peak response at $5 \mathrm{~Hz}$ and $10 \mathrm{~Hz}$ was calculated as a percentage of the response obtained at $0.3 \mathrm{~Hz}$. FDD data $(\mathrm{n}=8-$ 13 animals/group) is presented as mean \pm SEM.

After completion of the terminal experiment, rats were overdosed with Euthasol $(390 \mathrm{mg} / \mathrm{kg}$ sodium pentobarbital and $50 \mathrm{mg} / \mathrm{kg}$ phenytoin, i.p.) and the animal was either transcardiacally perfused with cold saline followed by $4 \%$ paraformaldehyde in PBS or fresh tissue was extracted for western blotting. 


\section{Extraction of fresh tissue and Western blotting}

Blocks of spinal tissue (L4-L5) were lysed in modified RIPA buffer (50mM Tris buffer $\mathrm{pH} 6.8$, $1 \%$ Triton-X, $0.1 \%$ SDS, $1 \mathrm{mM}$ DTT, $0.5 \%$ deoxycholate, $150 \mathrm{mM} \mathrm{NaCl}$ ) containing protease and phosphatase inhibitors (Roche), $2 \mathrm{mM}$ PMSF and $1 \mathrm{mM} \mathrm{NaF}$. Protein concentration was determined

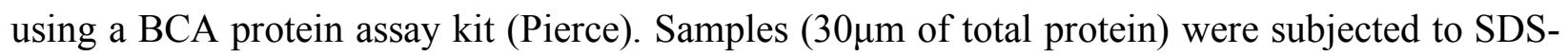
PAGE (10-16\% gels for BDNF, 4-20\% gradient TGX gels (Biorad) for KCC2/NKCC1). Antibodies were targeted against KCC2 (1:1000, Millipore), BDNF (1:1000; Santa Cruz) or mouse T4 monoclonal antibody against NKCC (1:1000, Developmental Studies Hybridoma Bank), followed by incubation with HRP-conjugated secondary antibody (Jackson ImmunoResearch). Optical densities of protein bands were performed using Image J. Values for each sample were averaged, normalized to actin and combined for each group. Western blot data ( $\mathrm{n}=6-11 /$ group) is presented as a ratio of the intact group.

\section{Tissue preparation and immunohistochemistry}

Spinal cord tissue was post-fixed overnight at $4^{\circ} \mathrm{C}$, transferred to $30 \%$ sucrose for cryoprotection and cut transversally ( $40 \mu \mathrm{m}$ sections) using a cryostat. Free floating sections were permeated in PBS containing 5\% donkey serum and $0.1 \%$ Triton X-100 for one hour at room temperature and incubated with antibodies targeted against KCC2 (1:1000; Millipore) and ChAT (1:100, Millipore) for 24h. After brief washes in PBS, spinal cord sections were incubated in secondary antibody conjugated to FITC and rhodamine (1:400; Jackson Immunoresearch) for two hours at room temperature. Stacked images of motoneurons ( $40 \mu \mathrm{m}$ sections) were acquired with a spectral confocal \& multiphoton system (Leica TCS SP2). The fluorescence intensity of KCC2 immunolabelling on the plasma membrane of motoneurons (identified by $\mathrm{ChAT}^{+}$, typical large size, and location within the ventral horn) was measured by averaging the integrated area of the density curve obtained by drawing three lines across each motoneurons (six data points) using ImageJ software (Côté et al., 2014). A minimum of three lumbar motoneurons were averaged per animal ( $\mathrm{n}=5-8$ animals/group). 


\section{Statistical analysis}

Significant differences for the properties of the M-wave and H-reflex as well as immunoblotting data were determined by either using a one-way ANOVA followed by the Holm-Sidak or a Kruskal-Wallis one-way ANOVA on ranks followed by Dunn's method if the sample variables did not fit a normal distribution (Shapiro-Wilk) or were not equally variant (Brown-Forsythes). Significant effects on the amplitude of the H-reflex by stimulation frequency and treatment group for the FDD were determined by a two-way ANOVA followed by the Holm-Sidak post-hoc test and the possible interaction of these factors with the variable was determined. Linear regression analysis was used to correlate $\mathrm{NKCC} 1$ to $\mathrm{KCC} 2$ and $\mathrm{KCC} 2$ to $\mathrm{BDNF}$ protein levels obtained by western blotting. All data are presented as mean \pm SEM. Statistical analysis was performed using Sigma Plot software 14.0 and statistically significant levels were set to $\mathrm{P}<0.05$.

\section{Results}

\section{KCC2 activity is required for H-reflex recovery after chronic SCI}

$\mathrm{SCI}$ induces a reduction in KCC2 expression in the lumbar enlargement of the spinal cord that is associated with the establishment and maintenance of spasticity after SCI (Boulenguez et al., 2010). Our earlier findings illustrate that motor training prevents the injury-induced decrease in KCC2 expression on lumbar motoneurons and reduces spasticity (Côté et al., 2014), but a causal relationship remained to be established. We therefore hypothesized that the decrease in hyperreflexia triggered by exercise requires $\mathrm{KCC} 2$ activity. We developed an intrathecal catheter delivery method to assess the effect of pharmacological inhibition of $\mathrm{KCC} 2$ on activity-dependent H-reflex recovery after SCI. KCC2 activation was specifically and only prevented during the daily rehabilitation session for 4 weeks post-SCI (Fig. 1B) at which time the properties of the H-reflex as well as its modulation was assessed. Because of its monosynaptic nature, the location of the neuroplasticity triggered by the injury and or inhibition is limited to primary afferent from group Ia fibers, $\alpha$-motoneuron and their synaptic connection. In response to a tibial nerve stimulation, two successive responses can be recorded from the interosseous muscle, i.e. the M-wave results from the direct activation of motor axons while the H-reflex is evoked by the activation of Ia afferents that form a monosynaptic connection with motoneurons (Fig. 2A). 
The recruitment curve was used to determine the amplitude of the maximal $m$-wave $\left(M_{\max }\right)$, the response of all motor units with supramaximal stimulation of axons of the tibial nerve, and of the maximal H-reflex amplitude $\left(\mathrm{H}_{\max }\right)$. To assess the relative proportion of motoneurons recruited through the monosynaptic reflex loop vs. the activation of the entire motor pool, the $\mathrm{H}_{\max } / \mathrm{M}_{\max }$ ratio was also calculated. The $\mathrm{H}_{\max } / \mathrm{M}$ ratio was also used to evaluate the relative activation of the motor pool required to reach maximal reflex amplitude. Neither SCI nor VU0240551 affected the M-wave or H-reflex latency, the amplitude of the maximal $\mathrm{M}$-wave $\left(\mathrm{M}_{\max }\right)$ and $\mathrm{H}-\mathrm{reflex}\left(\mathrm{H}_{\max }\right)$, the stimulation intensity at which $\mathrm{H}_{\max }$ is evoked and the stimulation threshold to evoke a M-wave (Table 1). However, rehabilitation prevented the decrease in the stimulation intensity required to evoke a H-reflex after SCI. More importantly, blocking KCC2 activity prevented the effect of exercise with H-reflex thresholds similar to unexercised SCI but significantly lower than intact. Together, these results suggest that the decrease in H-reflex excitability triggered by exercise after a chronic SCI requires KCC2 activity.

After SCI, the excitability of the spinal cord gradually increases as a result of the injury. The transition to a state of hyperreflexia is well established by one-month after SCI (Bennett et al., 1999; Yates et al., 2008) and the reduction in the low frequency-dependent depression (FDD) of the H-reflex widely accepted as a reliable correlate of spasticity (Thompson et al., 1992; Grey et al., 2008; Boulenguez et al., 2010). The improvement in FDD observed in exercised animals after $\mathrm{SCI}$ is characterized by the presence of a clear depression following a series if stimulations at $10 \mathrm{~Hz}$ (Fig. 2C) while the depth of the modulation is much shallower in an animal not undergoing a rehabilitation program (Fig.2B). VU0240551 prevented the activity-dependent recovery triggered by exercise and the FDD was very modest FDD (Fig.2D). If some level of H-reflex modulation is still present after SCI regardless of exercise or VU0240551, as all groups displayed a decrease in H-reflex amplitude as the stimulation frequency increased, there was a remarkable difference in the depth of modulation across groups (Fig.3A-D). Figure 3E shows the averaged FDD for each group at each frequency expressed as a percentage of the response at $0.3 \mathrm{~Hz}$, a frequency at which there is no or little depression of the H-reflex. Higher H-reflex amplitude depicts less depression of the reflex. A two-way ANOVA revealed statistically significant differences across stimulation frequency $(\mathrm{P}<0.001)$ and across experimental groups $(\mathrm{P}<0.001)$ with a significant interaction 
between frequency and groups $(\mathrm{P}<0.001)$. Post-hoc comparisons suggested that 5 and $10 \mathrm{~Hz}$ values were different from $0.3 \mathrm{~Hz}$ in all groups $(\mathrm{P}<0.001)$. The FDD drastically decreased after SCI with the amplitude of the H-reflex increasing from $13 \pm 3 \%$ to $57 \pm 7 \%$ at $5 \mathrm{~Hz}$ and from $6 \pm 2 \%$ to $46 \pm 6 \%$ at $10 \mathrm{~Hz}$. Rehabilitation prevented this decrease with values not significantly different from uninjured animals at $5 \mathrm{~Hz}$ and $10 \mathrm{~Hz}(24 \pm 2 \%$ and $6 \pm 2 \%$ respectively), but considerably lower (i.e. more depression) than SCI. Blocking KCC2 prevented the recovery of FDD observed in exercised animals. VU0240551 significantly decreased the depression observed in exercised animals and had a FDD similar to $\mathrm{SCI}$ at $5 \mathrm{~Hz}$ and $10 \mathrm{~Hz}(47 \pm 6 \%$ and $40 \pm 6 \%)$. These results suggest that exercise failed to return H-reflex modulation after a chronic SCI when KCC2 cannot be activated during training.

The $\mathrm{H}_{\max } / \mathrm{M}_{\max }$ ratio, which estimates the fraction of motoneurons recruited relative to the activation of the entire motor pool, and is recognized as an estimate of motoneuronal excitability, was also significantly different across groups $(\mathrm{P}<0.001)$. Blocking $\mathrm{KCC} 2$ during rehabilitation sessions prevented the activity-dependent decrease in the $\mathrm{H}_{\max } / \mathrm{M}_{\max }$ ratio with SCI+Ex+VU0240551 animals displaying similar values to SCI but significantly higher than exercised and intact (Fig. 3F). This further support that $\mathrm{KCC} 2$ activity is required for the activitydependent decrease in spinal hyperexcitability.

\section{BDNF activity is required for H-reflex recovery after chronic SCI}

Because BDNF-TrkB signaling is known as a potent regulator of $\mathrm{KCC} 2$ in neurons (Rivera et al., 2002; 2004; Coull et al., 2005; Ferrini and De Koninck, 2013), we sought to further consider a causal relationship between the upregulation of BDNF and $\mathrm{KCC} 2$. If such a link exists after chronic SCI, preventing BDNF action, specifically during the training session, should prevent both the increase in $\mathrm{KCC} 2$ expression and the exercise-dependent recovery of the H-reflex modulation. We first examined the effect of the BDNF-sequestering TrkB-IgG on H-reflex properties.

Similar to what we observed when blocking KCC2 activity, chelating endogenous BDNF did not modify any features of the H-reflex but for the stimulation threshold to initiate a response (Table 1). TrkB-IgG prevented rehabilitation to restore the stimulation intensity required to initiate a $\mathrm{H}$ - 
reflex close to intact levels and this group displayed values similar to the SCI group and significantly lower than intact. This suggests that the decrease in H-reflex excitability triggered by exercise after SCI not only requires KCC2 activity, but also BDNF signaling. Scavenging BDNF also prevented the activity-dependent decrease in the $\mathrm{H}_{\max } / \mathrm{M}_{\max }$ ratio with values similar to SCI and SCI+Ex+VU0240551 (Fig.3F).

Similar to VU0240551 (Fig. 2D), TrkB-IgG prevented the activity-dependent recovery triggered by exercise and the FDD was very modest FDD (Fig. 2E and 3D). Overall, scavenging BDNF significantly prevented the activity-dependent recovery of the FDD (Fig. 3E) (5 and 10Hz, $\mathrm{P}<0.001)$ and H-reflex amplitude values were no different from unexercised SCI or exercised animals that had received VU0240551. This provides evidence that rehabilitation fails to reduce hyperexcitability in spinal networks after SCI when BDNF activity was prevented. Blocking BDNF or KCC2 activity yielded very comparable results.

\section{Blocking KCC2 or scavenging BDNF after SCI does not affect hyperreflexia in unexercised animals}

To exclude any confounding factor and verify that the results observed are not simply due to the effect of the drugs on spinal networks rather than blocking the exercise-dependent recovery of the H-reflex modulation, we assessed if there was any effect of blocking $\mathrm{KCC} 2$ or BDNF activity in unexercised SCI rats. When comparing SCI animals that received VU0240551 or TrkB-IgG to animals that received the vehicle, none of the general features of the M-wave and H-reflex were significantly altered 4 weeks post-SCI (Table 1). These results suggest that, at this dose, drugs alone had no effect on spinal excitability when no rehabilitation program was implemented. Similarly, the modulation of the H-reflex was not different after SCI whether a drug treatment was used or not (not shown). The FDD of SCI animals that received VU0240551 or TrkB-IgG was not statistically different from SCI animals receiving the vehicle, with all groups displaying a very modest depression at both $5 \mathrm{~Hz}$ (respectively $41 \pm 5 \%, 47 \pm 6,57 \pm 7 \% \%$ ) and $10 \mathrm{~Hz}$ and $(30 \pm 5 \%$, $32 \pm 5 \%, 46 \pm 6 \%$ ). This confirms that blocking KCC2 or BDNF activity had no effect after SCI in untrained animals when $\mathrm{KCC} 2$ and BDNF levels are already low in the spinal cord and suggests that the drug itself does not impact motor recovery. No further analysis was carried out on these 
control groups as the objective of the study is to investigate if $\mathrm{KCC} 2$ is critical to the beneficial effect of activity-based therapies.

\section{BDNF signaling is required for the activity-dependent increase in $\mathrm{KCC} 2$ expression}

We then performed western blot analysis on tissue from the lumbar enlargement to evaluate the effect of blocking KCC2 or BDNF activity. One-way ANOVA confirmed differences in KCC2 protein expression across groups $(\mathrm{P}<0.001)$. Further post hoc analysis showed that KCC2 expression is modulated after SCI, decreasing to $64 \pm 3 \%$ of intact values (Fig. 4A, see also Côté $e t$ al., 2014). Interestingly, the injury-induced downregulation in KCC2 expression was prevented by the rehabilitation program, whether KCC2 activity was blocked or not, with KCC2 expression levels not different from intact. This suggests that VU0240551 only affected KCC2 activity, but did not affect protein synthesis. On the contrary, scavenging BDNF prevented the activitydependent increase in $\mathrm{KCC} 2$ expression with values similar to unexercised animals $(63 \pm 5 \%)$ and lower than intact or exercised animals with, suggesting that BDNF activity is required to restore KCC2 expression induced by exercise.

One-way ANOVA also confirmed a difference in BDNF protein expression between groups $(\mathrm{P}<0.001)$. Exercise prevents the decrease in BDNF expression after a chronic SCI (Fig. 4B). Animals that followed a rehabilitation program had higher BDNF expression levels as compared to unexercised SCI, and scavenging BDNF during training yielded lower levels. Surprisingly, blocking KCC2 activity prevented the beneficial effect of exercise on BDNF levels with values significantly lower than exercised animals receiving the vehicle, suggesting a mechanism by which $\mathrm{KCC} 2$ can regulate BDNF levels.

A regression analysis showed that there is a significant linear relationship between BDNF and KCC2 expression in the lumbar enlargement of the spinal cord (Fig.5A). Data from SCI that received the vehicle or TrkB-IgG are clustered in the lower left quadrant with low expression levels of both BDNF and KCC2 while intact and SCI animals that followed a rehabilitation program are grouped in the top right quadrant displaying higher levels of both proteins. This further supports a role for BDNF in regulating $\mathrm{KCC} 2$. 
Although the shift in chloride homeostasis and impaired FDD after chronic SCI was shown to depend on a decrease in KCC2 expression (Boulenguez et al., 2010), the inwardly directed $\mathrm{Na}^{+}$$\mathrm{K}^{+}-\mathrm{Cl}^{-}$cotransporter isoform 1, NKCC1, is also upregulated after SCI (Cramer et al., 2008; Hasbargen et al., 2010; Lee et al., 2014). The relative expression of KCC2 and NKCC1 critically determine $\left[\mathrm{Cl}^{-}\right]_{\mathrm{i}}$ and GABA-mediated responses. $\mathrm{NKCC} 1$ is responsible to bring $\mathrm{Cl}^{-}$in the cell, in opposition to $\mathrm{KCC} 2$, so that a simultaneous decrease in $\mathrm{KCC} 2$ and increase in NKCC1 after SCI (Coté et al., 2014) would act synergistically to depolarize $\mathrm{E}_{\mathrm{Cl}^{-}}$. We therefore measured changes in $\mathrm{NKCC} 1$ protein expression in the lumbar enlargement and found a significant difference between groups (Fig. 4C, $\mathrm{P}=0.003$ ). Rehabilitation returned $\mathrm{NKCC1}$ expression levels close to intact values $(93 \pm 4 \%)$ with significantly less $\mathrm{NKCC} 1$ in the lumbar enlargement than unexercised SCI animals $(147 \pm 14 \%)$. VU0240551 prevented the restoration of NKCC1 expression levels following a rehabilitation program with values not different from unexercised SCI animals $(161 \pm 24 \%)$ but higher than exercised. Scavenging BDNF did not affect NKCC1 expression $(97 \pm 16 \%)$. This suggests that NKCC1 is also modulated in an activity-dependent manner after SCI and may contribute to the shift in chloride homeostasis induced by exercise. A regression analysis was also carried out to address the expression of $\mathrm{NKCC} 1$ in the lumbar spinal cord as a function of KCC2. We observed a significant negative relationship between NKCC1 and KCC2 expression levels in the lumbar spinal cord (Fig.5B). Consistent with their opposing directionality in chloride transport, this supports previous findings suggesting that $\mathrm{NKCC} 1$ and $\mathrm{KCC} 2$ protein levels are reciprocally regulated.

As hyperreflexia and spasticity are specifically associated with a KCC2 increase in motoneuronal membrane in the lumbar enlargement (Boulenguez et al., 2010), we sought to investigate if the BDNF dependent increase in KCC2 expression involved in activity-dependent recovery occurs at this specific location. In the ventrolateral spinal cord, $\mathrm{KCC} 2$ labelling is particularly strong around the motoneuronal membrane (Fig. 6). Exercise increased KCC2 expression around the motoneuronal membrane and less cytoplasmic clusters are visible in the soma, suggesting a decrease in the internalization of KCC2 into vesicles. Blocking KCC2 or BDNF activity during exercise prevented this effect, i.e. the activity-dependent restoration of $\mathrm{KCC} 2$ around the motoneuronal membrane was not observed. 


\section{Discussion}

Rehabilitation approaches that promote repetitive motor activity are widely used in the clinic and are a critical component of successful functional recovery in SCI individuals. A variety of exercise programs have revealed potential to alleviate spasticity, but the molecular pathways involved in functional recovery remains elusive. Here, we show for the first time that 1) KCC2 activity is required to the beneficial effect of exercise on spasticity; 2) this activity-dependent increase in $\mathrm{KCC} 2$ levels is regulated by BDNF.

\section{KCC2 activity is required to decrease spasticity after chronic SCI}

Under physiological conditions, $\mathrm{KCC} 2$ extrudes $\mathrm{Cl}^{-}$from neurons maintaining low levels of $\left[\mathrm{Cl}^{-}\right]$. This insures that GABAergic synaptic transmission remains hyperpolarizing as $\mathrm{Cl}^{-}$flows inwardly along its electrochemical gradient. A condition that negatively affects KCC2 function leads to an accumulation of $\left[\mathrm{Cl}^{-}\right]_{\mathrm{i}}$ which undermines $\mathrm{GABA}_{\mathrm{A}}$-mediated inhibition (Rivera et al., 1999; Hübner et al., 2001; Coull et al., 2003). In spinal motoneurons, genetic or pharmacological manipulations that decrease $\mathrm{KCC} 2$ expression/function elicit a $\sim 10-20 \mathrm{mV}$ depolarizing shift in $\mathrm{E}_{\mathrm{Cl}}$ - which increases neuronal excitability and impairs postsynaptic inhibition (Hübner et al., 2001; JeanXavier et al., 2006; Bos et al., 2013). Similarly, the SCI-induced decrease in motoneuronal KCC2 expression and subsequent shift in chloride homeostasis also contributes to spinal hyperexcitability and spasticity (Boulenguez et al., 2010; Mòdol et al., 2014). SCI, as other CNS pathologies, recapitulate developmental programs with low levels of KCC2 and consequent depolarizing shift in $\mathrm{E}_{\mathrm{GABAA}}$ reminiscent of immature neurons (reviewed in Kaila et al., 2014a).

After chronic SCI, the loss of supraspinal control and increase in the gain of afferent feedback increases the excitability of spinal reflexes. This results in permanent undesirable effects such as inappropriate timing of activation of muscles during movement and failure to adjust reflex excitability to meet task requirements. Rehabilitation programs can both restore KCC2 expression on lumbar motoneurons and improve reflex recovery (Côté et al., 2014), but the causal relationship linking the shift in chloride homeostasis and the recovery of motor function remains unclear. Here, we have used a chronic delivery of VU0240551, a highly specific KCC2 blocker (Delpire et al., 
2009), to evaluate the functional role of KCC2 in motor recovery after SCI. We insured that its effect was specifically targeted to KCC2 function during rehabilitation (vs. spontaneous recovery) with a delivery protocol restricted to the exercise period and by taking advantage of its relatively short therapeutic window (Austin and Delpire, 2011).

We have used the FDD, which is indicative of the function of the spinal inhibitory system, is dependent on $\mathrm{GABA}_{\mathrm{A}}$ receptor-mediated inhibition in rodents and is associated to spasticity (Jolivalt et al., 2008; Boulenguez et al., 2010; Lee-Kubli and Calcutt, 2014). The lack of significant effect of VU0240551 in unexercised SCI animals suggests a low target availability and confirms that our observations are not solely relying on the effect of the drug, but to its interaction with activity-based therapy. While blocking KCC2 with VU0240551 did not affect KCC2 expression in the lumbar enlargement, confocal analysis distinctly illustrated a decrease expression on motoneuronal membrane. This supports findings suggesting that VU0240551 mainly affects posttranslational mechanisms (vs. protein synthesis), including preventing shuttling to the membrane, which is also supported by the increased presence of clusters in the cytoplasm (Fig. 6A).

In agreement with our earlier studies, animals that underwent a rehabilitation program after SCI displayed much less spinal hyperexcitability (Côté et al., 2011; 2014). VU0240551 prevented the activity-dependent recovery of reflex modulation, indicating that the beneficial effect of exercise is critically dependent on KCC2 activity. Together, our data suggests that rehabilitation increases both KCC2 synthesis (Fig. 4A) and post-translational mechanisms responsible for KCC2 trafficking to the membrane (Fig., 6A). Such mechanisms include increased insertion rate to the membrane and/or decreased internalization by endocytosis (Lee et al., 2007).

\section{Activity-dependent modulation of KCC2 protein is BDNF-dependent}

KCC2 is dynamically modulated by multiple intra- and intercellular signaling pathways (Fiumelli and Woodin, 2007), with the most prevalent being BDNF signaling onto TrkB receptors (TrkB; Rivera et al., 2002; 2004; Coull et al., 2005; Ferrini and De Koninck, 2013). The polarity of BDNF-dependent regulation of KCC2 expression differs depending on the developmental stage and the integrity of the CNS. While BDNF reduces GABAergic inhibition through KCC2 
downregulation in mature neurons (Rivera et al., 2002; 2004; Coull et al., 2005; Boulenguez et al., 2010; Huang et al., 2017), it promotes an increase in KCC2 expression in embryonic neurons or following an axotomy in the adult (Aguado et al., 2003; Payne et al., 2003; Carmona et al., 2006).

After a chronic SCI, activity-based therapies increase $\mathrm{KCC} 2$ and BDNF levels in the lumbar spinal cord (Côté et al., 2014; Chopek et al., 2015; Tashiro et al., 2015). Increased BDNF levels is associated with the normalization of motoneuronal properties (Beaumont et al., 2008) and locomotor recovery (Boyce et al., 2007; 2012; Ying et al., 2008), and is positively correlated to the restoration of reflex modulation, suggesting a linear relationship with hyperreflexia (Côté et al., 2011). Interestingly, BDNF upregulates $\mathrm{KCC} 2$ in $\mathrm{SDH}$ neurons and attenuate central sensitization through reinstating GABAergic inhibition (Huie et al., 2012; Huang et al., 2017). In order to identify BDNF-TrkB as an activity-dependent regulator of $\mathrm{KCC} 2$ after SCI, we used a TrkB-IgG, a chimeric molecule comprised of the extracellular domain of TrkB that sequesters BDNF by competing with endogenous TrkB. TrkB-IgG delivered during training yielded lower levels of BDNF as compared to exercised animals that received the vehicle, confirming that TrkBIgG treatment was effective at scavenging BDNF. Our results illustrate that depleting BDNF availability not only prevented the rehabilitation-induced recovery of the FDD, but more importantly the increase in $\mathrm{KCC} 2$ motoneuronal expression triggered by exercise. This indicate that BDNF contributes to decrease hyperreflexia after SCI through regulating KCC2 expression and restoring chloride homeostasis after SCI.

In the hippocampus, enhanced membrane insertion and retention of KCC2 depends on BDNFTrkB signaling in response to increased network activity (Khirug et al., 2010; Puskarjov et al., 2015). The results presented here provide evidence that a similar mechanism is at play in the spinal cord. Chronic SCI recapitulates an earlier developmental state in which BDNF promotes KCC2 upregulation and restores GABA-mediated inhibition. Our results suggest that the activitydependent activation of BDNF/TrkB alters chloride extrusion and the global inhibitory action of $\mathrm{GABA}_{\mathrm{A}}$-mediated responses as depicted by the restoration of the FDD in exercised animals. Among several possibilities, TrkB activation can regulate calpains (Zadran et al., 2010). Interestingly, calpain-dependent proteolytic cleavage of $\mathrm{KCC} 2$ alters its ability to extrude $\mathrm{Cl}^{-}$in 
the hippocampus and spinal cord (Puskarjov et al., 2012; Zhou et al., 2012) and contributes to the development of spasticity after SCI (Brocard et al., 2016; Plantier and Brocard, 2017). Whether activity-dependent plasticity affects this pathway in motoneurons remains to be determined.

It is also worth noting that not only does chelating BDNF decreases KCC2 expression (Fig. 4A), but blocking KCC2 also appears to decrease BDNF levels in exercised animals (Fig. 4B). This suggest the presence of a retroactive feedback loop through which KCC2 can also regulate BDNF expression.

\section{BDNF is not responsible for the exercise-induced reciprocal regulation of $\mathrm{KCC} 2$ and NKCC1}

Activity-dependent plasticity triggered by exercise after SCI not only increases the expression of KCC2 but also decreases the expression of the chloride intruder NKCC1 (Fig. 4C, see also Côté et al., 2014), as both transporters act in synergy to restore $\left[\mathrm{Cl}^{-}\right]_{\mathrm{i}}$. VU0240551 prevented the effect of exercise on both $\mathrm{KCC} 2$ and $\mathrm{NKCC} 1$, so that their expression levels in the lumbar spinal cord maintained a negative correlation. Because NKCC1 staining did not reveal strong enough staining on motoneuronal membrane, but is strongly expressed in small glial cells surrounding motoneurons (Kanaka et al., 2001) as well as primary afferent terminal (Stil et al., 2009), identifying with precision if its expression was specifically downregulated in motoneurons was not possible.

Scavenging BDNF did not affect NKCC1 expression, suggesting that BDNF is not responsible for the activity-dependent reciprocal regulation of $\mathrm{KCC} 2$ and $\mathrm{NKCC} 1$. $\mathrm{NKCC} 1$ and $\mathrm{KCC} 2$ activity is regulated in a reciprocal fashion through the WNK-SPAK/OSR1 pathway, i.e. WNKs inactivates KCC2 and activates NKCC1, providing a coordinated control over $\left[\mathrm{Cl}^{-}\right]_{\mathrm{i}}$ (Kahle et al., 2010, Alessi et al., 2014). Decreasing WNK1 activity triggers a hyperpolarizing shift in GABA responses by enhancing $\mathrm{KCC} 2$-mediated $\mathrm{Cl}^{-}$extrusion (Friedel et al., 2015) and reduces allodynia and hyperalgesia in SDH neurons (Kahle et al., 2016). The WNK1 pathway can be activated by lower levels of $\left[\mathrm{Cl}^{-}\right] \mathrm{i}$, a hallmark of SCI. Anecdotical reports suggest the involvement of WNKSPAK/OSR1 pathway in activating NKCC1 at the lesion site after SCI (Lee et al., 2014) but 
warrants further studies. Whether activity-based therapies decrease WNK1 activity remains to be determined, but our results strongly support this possibility.

\section{Therapeutic significance}

Available anti-spastic drugs such as baclofen, diazepam, tizanidine and botulinum toxin have serious side effects including sedation, dizziness and a deep, long-lasting depression of spinal excitability that significantly reduces muscle activity and interferes with motor recovery (Dario and Tomei, 2004; Adams and Hicks, 2005; Elbasiouny et al., 2010; Angeli et al., 2012). The hyperexcitability of spinal networks in SCI individuals often leads to spasticity and co-contraction of flexor and extensor muscles due to less inhibitory reflexes (Boorman et al., 1996; Mazzocchio and Rossi, 1997; Katz, 1999; Harkema, 2008). Inhibitory synapses constitute about 30\% of all synapses in the spinal cord and are critical for the optimal function of neural circuits by regulating oscillatory behavior of neuronal networks, contributing to multifaceted aspects of neuronal processing, and limiting the extent of excitatory activity when required. Given the role of KCC2 in regulating the strength of inhibitory synaptic transmission, facilitating neuronal $\mathrm{Cl}^{-}$extrusion by directly targeting KCC2 has emerged as a promising alternative (Doyon et al., 2013; Kahle et al., 2014). This study illustrates for the first time that the beneficial effect of exercise on spinal hyperexcitability requires the activation of the BDNF-KCC2 pathway to maintain chloride homeostasis in motoneurons after SCI. While BDNF is effective in improving spasticity, longterm administration has shown serious therapeutic drawbacks (Weishaupt et al., 2012; Fouad et al., 2013).

Targeting $\mathrm{Cl}^{-}$transport by activating $\mathrm{KCC} 2$ and enhancing chloride extrusion can modulate GABAergic transmission in vivo and decrease neuropathic pain and hyperalgesia (Gagnon et al., 2013; Ferrini et al., 2017). This critically identifies this pathway as a potential pharmacological therapeutic target to improve hyperreflexia after a chronic SCI for individuals with comorbidities that delays the onset of physical therapy. Acting directly on chloride homeostasis would help to restore endogenous inhibition rather than actively depress excitability. 


\section{ACKNOWLEDGEMENTS:}

We are in debt to Emerita Professor Marion Murray and Dr. Michel Lemay for their significant criticisms, comments, input and exchange of ideas on earlier versions of this manuscript.

\section{Funding}

This work was supported by grants from the National Institute of Neurological Disorders and Stroke (RO1 NS083666) and the Craig H. Neilsen Foundation (189758).

\section{Competing interests}

The authors report no competing interests 
bioRxiv preprint doi: https://doi.org/10.1101/489740; this version posted December 7, 2018. The copyright holder for this preprint (which was not certified by peer review) is the author/funder, who has granted bioRxiv a license to display the preprint in perpetuity. It is made available under aCC-BY 4.0 International license.

\section{References}

Adams MM, Hicks AL. Spasticity after spinal cord injury. Spinal Cord 2005; 43: 577-86.

Aguado F, Carmona MA, Pozas E, Aguilo A, Martinez-Guijarro FJ, Alcantara S, et al. BDNF regulates spontaneous correlated activity at early developmental stages by increasing synaptogenesis and expression of the $\mathrm{K}^{+} / \mathrm{Cl}^{-}$co-transporter $\mathrm{KCC} 2$. Development 2003; 130: 1267-80.

Alessi DR, Zhang J, Khanna A, Hochdorfer T, Shang Y, Kahle KT. The WNK-SPAK/OSR1 pathway: master regulator of cation-chloride cotransporters. Sci Signal 2014; 7: re3.

Angeli C, Ochsner J, Harkema S. Effects of chronic baclofen use on active movement in an individual with a spinal cord injury. Spinal Cord 2012; 50: 925-7.

Austin TM, Delpire E. Inhibition of KCC2 in mouse spinal cord neurons leads to hypersensitivity to thermal stimulation. Anesth Analg 2011; 113: 1509-15.

Beaumont E, Kaloustian S, Rousseau G, Cormery B. Training improves the electrophysiological properties of lumbar neurons and locomotion after thoracic spinal cord injury in rats. Neurosci Res 2008; 62: 147-54.

Bennett DJ, Gorassini M, Fouad K, Sanelli L, Han Y, Cheng J. Spasticity in rats with sacral spinal cord injury. J Neurotrauma 1999; 16: 69-84.

Boorman GI, Lee RG, Becker WJ, Windhorst UR. Impaired "natural reciprocal inhibition" in patients with spasticity due to incomplete spinal cord injury. Electroencephalogr Clin Neurophysiol 1996; 101: 84-92.

Bos R, Sadlaoud K, Boulenguez P, Buttigieg D, Liabeuf S, Brocard C, et al. Activation of 5$\mathrm{HT} 2 \mathrm{~A}$ receptors upregulates the function of the neuronal $\mathrm{K}-\mathrm{Cl}$ cotransporter $\mathrm{KCC} 2$. Proc Natl Acad Sci USA 2013; 110: 348-53.

Boulenguez P, Liabeuf S, Bos R, Bras H, Jean-Xavier C, Brocard C, et al. Down-regulation of the potassium-chloride cotransporter $\mathrm{KCC} 2$ contributes to spasticity after spinal cord injury. Nat Med 2010; 16: 302-7.

Boyce VS, Mendell LM. Neurotrophic factors in spinal cord injury. Handb Exp Pharmacol 2014a; 220: 443-60.

Boyce VS, Mendell LM. Neurotrophins and spinal circuit function. Front Neural Circuits 2014b; 8: 59.

Boyce VS, Park J, Gage FH, Mendell LM. Differential effects of brain-derived neurotrophic factor and neurotrophin-3 on hindlimb function in paraplegic rats. Eur J Neurosci 2012; 35: 221-32.

Boyce VS, Tumolo M, Fischer I, Murray M, Lemay MA. Neurotrophic factors promote and enhance locomotor recovery in untrained spinalized cats. J Neurophysiol 2007; 98: 1988-96.

Brocard C, Plantier V, Boulenguez P, Liabeuf S, Bouhadfane M, Viallat-Lieutaud A, et al. Cleavage of $\mathrm{Na}(+)$ channels by calpain increases persistent $\mathrm{Na}(+)$ current and promotes spasticity after spinal cord injury. Nat Med 2016; 22: 404-11.

Carmona MA, Pozas E, Martinez A, Espinosa-Parrilla JF, Soriano E, Aguado F. Age-dependent spontaneous hyperexcitability and impairment of GABAergic function in the hippocampus of mice lacking trkB. Cereb Cortex 2006; 16: 47-63.

Chopek JW, Sheppard PC, Gardiner K, Gardiner PF. Serotonin receptor and KCC2 gene expression in lumbar flexor and extensor motoneurons posttransection with and without passive cycling. J Neurophysiol 2015; 113: 1369-76. 
Côté M-P, Azzam GA, Lemay MA, Zhukareva V, Houle JD. Activity-dependent increase in neurotrophic factors is associated with an enhanced modulation of spinal reflexes after spinal cord injury. J Neurotrauma 2011; 28: 299-309.

Côté M-P, Gandhi S, Zambrotta M, Houle JD. Exercise modulates chloride homeostasis after spinal cord injury. J Neurosci 2014; 34: 8976-87.

Coull JA, Beggs S, Boudreau D, Boivin D, Tsuda M, Inoue K, et al. BDNF from microglia causes the shift in neuronal anion gradient underlying neuropathic pain. Nature 2005; 438: 1017-21.

Coull JA, Boudreau D, Bachand K, Prescott SA, Nault F, Sik A, et al. Trans-synaptic shift in anion gradient in spinal lamina I neurons as a mechanism of neuropathic pain. Nature 2003; 424: 938-42.

Cramer SW, Baggott C, Cain J, Tilghman J, Allcock B, Miranpuri G, et al. The role of cationdependent chloride transporters in neuropathic pain following spinal cord injury. Mol Pain 2008; $4: 36$.

Dario A, Tomei G. A benefit-risk assessment of baclofen in severe spinal spasticity. Drug Saf 2004; 27: 799-818.

Delpire E. Cation-Chloride Cotransporters in Neuronal Communication. News Physiol Sci 2000; 15: 309-12.

Delpire E, Days E, Lewis LM, Mi D, Kim K, Lindsley CW, et al. Small-molecule screen identifies inhibitors of the neuronal $\mathrm{K}-\mathrm{Cl}$ cotransporter KCC2. Proc Natl Acad Sci USA 2009; 106: 5383-8.

Dietz V (2001) Spinal cord lesion: effects of and prespectives for treatment. Neural Plast 8:8390.

Doyon N, Ferrini F, Gagnon M, De Koninck Y. Treating pathological pain: is KCC2 the key to the gate? Expert Rev Neurother 2013; 13: 469-71.

Ferrini F, De Koninck Y. Microglia control neuronal network excitability via BDNF signalling. Neural Plast 2013; 2013: 429815.

Ferrini F, Trang T, Mattioli TA, Laffray S, Del'Guidice T, Lorenzo LE, Castonguay A, Doyon N, Zhang W, Godin AG, Mohr D, Beggs S, Vandal K, Beaulieu JM, Cahill CM, Salter MW, De Koninck Y (2013) Morphine hyperalgesia gated through microglia-mediated disruption of neuronal Cl(-) homeostasis. Nat Neurosci 16:183-192.

Ferrini F, Lorenzo LE, Godin AG, Quang ML, De Koninck Y. Enhancing KCC2 function counteracts morphine-induced hyperalgesia. Sci Rep 2017; 7: 3870.

Fiumelli H, Woodin MA. Role of activity-dependent regulation of neuronal chloride homeostasis in development. Curr Opin Neurobiol 2007: 17: 81-6.

Fouad K, Bennett DJ, Vavrek R, Blesch A. Long-term viral brain-derived neurotrophic factor delivery promotes spasticity in rats with a cervical spinal cord hemisection. Front Neurol 2013; $4: 187$.

Friedel P, Kahle KT, Zhang J, Hertz N, Pisella LI, Buhler E, Schaller F, Duan J, Khanna AR, Bishop PN, Shokat KM, Medina I (2015) WNK1-regulated inhibitory phosphorylation of the KCC2 cotransporter maintains the depolarizing action of GABA in immature neurons. Sci Signal 8:ra65.

Gackiere F, Vinay L (2015) Contribution of the potassium-chloride cotransporter KCC2 to the strength of inhibition in the neonatal rodent spinal cord in vitro. J Neurosci 35:53075316. 
bioRxiv preprint doi: https://doi.org/10.1101/489740; this version posted December 7, 2018. The copyright holder for this preprint (which was not certified by peer review) is the author/funder, who has granted bioRxiv a license to display the preprint in perpetuity. It is made available under aCC-BY 4.0 International license.

Gagnon M, Bergeron MJ, Lavertu G, Castonguay A, Tripathy S, Bonin RP, et al. Chloride extrusion enhancers as novel therapeutics for neurological diseases. Nat Med 2013; 19 : 1524-8.

Gomez-Pinilla F, Huie JR, Ying Z, Ferguson AR, Crown ED, Baumbauer KM, et al. BDNF and learning: Evidence that instrumental training promotes learning within the spinal cord by up-regulating BDNF expression. Neuroscience 2007; 148: 893-906.

Grey MJ, Klinge K, Crone C, Lorentzen J, Biering-Sorensen F, Ravnborg M, et al. Postactivation depression of soleus stretch reflexes in healthy and spastic humans. Exp Brain Res 2008; 185: 189-97.

Harkema SJ. Plasticity of interneuronal networks of the functionally isolated human spinal cord. Brain Res Rev 2008; 57: 255-64.

Hasbargen T, Ahmed MM, Miranpuri G, Li L, Kahle KT, Resnick D, Sun D (2010) Role of NKCC1 and KCC2 in the development of chronic neuropathic pain following spinal cord injury. AnnNYAcadSci 1198:168-172.

Holtz KA, Lipson R, Noonan VK, Kwon BK, Mills PB. Prevalence and Effect of Problematic Spasticity After Traumatic Spinal Cord Injury. Arch Phys Med Rehabil 2017; 98: 1132-8.

Houle JD, Morris K, Skinner RD, Garcia-Rill E, Peterson CA. Effects of fetal spinal cord tissue transplants and cycling exercise on the soleus muscle in spinalized rats. Muscle Nerve 1999; 22: 846-56.

Huang YJ, Lee KH, Grau JW (2017) Complete spinal cord injury (SCI) transforms how brain derived neurotrophic factor (BDNF) affects nociceptive sensitization. Exp Neurol 288:38-50.

Hübner CA, Stein V, Hermans-Borgmeyer I, Meyer T, Ballanyi K, Jentsch TJ. Disruption of $\mathrm{KCC} 2$ reveals an essential role of $\mathrm{K}-\mathrm{Cl}$ cotransport already in early synaptic inhibition. Neuron 2001; 30: 515-24.

Huie JR, Garraway SM, Baumbauer KM, Hoy KC, Jr., Beas BS, Montgomery KS, Bizon JL, Grau JW (2012) Brain-derived neurotrophic factor promotes adaptive plasticity within the spinal cord and mediates the beneficial effects of controllable stimulation.

Neuroscience 200:74-90.

Hutchinson KJ, Gomez-Pinilla F, Crowe MJ, Ying Z, Basso DM. Three exercise paradigms differentially improve sensory recovery after spinal cord contusion in rats. Brain 2004; 127(Pt 6): 1403-14.

Jean-Xavier C, Pflieger JF, Liabeuf S, Vinay L. Inhibitory postsynaptic potentials in lumbar motoneurons remain depolarizing after neonatal spinal cord transection in the rat. $\mathrm{J}$ Neurophysiol 2006; 96: 2274-81.

Jolivalt CG, Lee CA, Ramos KM, Calcutt NA. Allodynia and hyperalgesia in diabetic rats are mediated by GABA and depletion of spinal potassium-chloride co-transporters. Pain 2008; 140: 48-57.

Kahle KT, Khanna A, Clapham DE, Woolf CJ. Therapeutic restoration of spinal inhibition via druggable enhancement of potassium-chloride cotransporter KCC2-mediated chloride extrusion in peripheral neuropathic pain. JAMA Neurol 2014; 71: 640-5.

Kahle KT, Rinehart J, Lifton RP. Phosphoregulation of the Na-K-2Cl and K-Cl cotransporters by the WNK kinases. Biochim Biophys Acta 2010; 1802: 1150-8.

Kahle KT et al. (2016) Inhibition of the kinase WNK1/HSN2 ameliorates neuropathic pain by restoring GABA inhibition. Sci Signal 9:ra32. 
bioRxiv preprint doi: https://doi.org/10.1101/489740; this version posted December 7, 2018. The copyright holder for this preprint (which was not certified by peer review) is the author/funder, who has granted bioRxiv a license to display the preprint in perpetuity. It is made available under aCC-BY 4.0 International license.

Kaila K, Price TJ, Payne JA, Puskarjov M, Voipio J. Cation-chloride cotransporters in neuronal development, plasticity and disease. Nat Rev Neurosci 2014a; 15: 637-54.

Kaila K, Ruusuvuori E, Seja P, Voipio J, Puskarjov M. GABA actions and ionic plasticity in epilepsy. Curr Opin Neurobiol 2014b; 26: 34-41.

Katz R. Presynaptic inhibition in humans: a comparison between normal and spastic patients. J Physiol (Paris) 1999; 93: 379-85.

Khirug S, Ahmad F, Puskarjov M, Afzalov R, Kaila K, Blaesse P. A single seizure episode leads to rapid functional activation of KCC2 in the neonatal rat hippocampus. J Neurosci 2010; 30: 12028-35.

Lee HH, Walker JA, Williams JR, Goodier RJ, Payne JA, Moss SJ. Direct protein kinase Cdependent phosphorylation regulates the cell surface stability and activity of the potassium chloride cotransporter KCC2. J Biol Chem 2007; 282: 29777-84.

Lee-Kubli CA, Calcutt NA. Altered rate-dependent depression of the spinal H-reflex as an indicator of spinal disinhibition in models of neuropathic pain. Pain 2014; 155: 250-60.

Leech KA, Hornby TG. High-Intensity Locomotor Exercise Increases Brain-Derived Neurotrophic Factor in Individuals with Incomplete Spinal Cord Injury. J Neurotrauma 2017; 34: 1240-8.

Lu B. BDNF and activity-dependent synaptic modulation. Learn Mem 2003; 10: 86-98.

Lu Y, Zheng J, Xiong L, Zimmermann M, Yang J. Spinal cord injury-induced attenuation of GABAergic inhibition in spinal dorsal horn circuits is associated with down-regulation of the chloride transporter KCC2 in rat. J Physiol 2008; 586: 5701-15.

Ludwig A, Uvarov P, Soni S, Thomas-Crusells J, Airaksinen MS, Rivera C. Early growth response 4 mediates BDNF induction of potassium chloride cotransporter 2 transcription. $\mathrm{J}$ Neurosci 2011; 31: 644-9.

Maynard FM, Karunas RS, Waring WP, 3rd. Epidemiology of spasticity following traumatic spinal cord injury. Arch Phys Med Rehab 1990; 71: 566-9.

Mazzocchio R, Rossi A. Involvement of spinal recurrent inhibition in spasticity. Further insight into the regulation of Renshaw cell activity. Brain 1997; 120 ( Pt 6): 991-1003.

Miletic G, Miletic V. Loose ligation of the sciatic nerve is associated with TrkB receptordependent decreases in KCC2 protein levels in the ipsilateral spinal dorsal horn. Pain 2008; 137: 532-9.

Mòdol L, Mancuso R, Ale A, Francos-Quijorna I, Navarro X. Differential effects on KCC2 expression and spasticity of ALS and traumatic injuries to motoneurons. Front Cell Neurosci 2014b; 8: 7.

Payne JA, Rivera C, Voipio J, Kaila K. Cation-chloride co-transporters in neuronal communication, development and trauma. Trends Neurosci 2003; 26: 199-206.

Petropoulou KB, Panourias IG, Rapidi CA, Sakas DE. The importance of neurorehabilitation to the outcome of neuromodulation in spasticity. Acta Neurochir Suppl 2007; 97(Pt 1): 243-50.

Plantier V, Brocard F. [Calpain as a new therapeutic target for treating spasticity after a spinal cord injury]. Med Sci (Paris) 2017; 33(6-7): 629-36.

Puskarjov M, Ahmad F, Kaila K, Blaesse P. Activity-dependent cleavage of the K-Cl cotransporter KCC2 mediated by calcium-activated protease calpain. J Neurosci 2012; 32: 11356-64.

Puskarjov M, Ahmad F, Khirug S, Sivakumaran S, Kaila K, Blaesse P. BDNF is required for seizure-induced but not developmental up-regulation of KCC2 in the neonatal hippocampus. Neuropharmacology 2015; 88: 103-9. 
Rivera C, Li H, Thomas-Crusells J, Lahtinen H, Viitanen T, Nanobashvili A, et al. BDNFinduced TrkB activation down-regulates the $\mathrm{K}+-\mathrm{Cl}$ - cotransporter $\mathrm{KCC} 2$ and impairs neuronal Cl- extrusion. J Cell Biol 2002; 159: 747-52.

Rivera C, Voipio J, Payne JA, Ruusuvuori E, Lahtinen H, Lamsa K, et al. The $\mathrm{K}+/ \mathrm{Cl}$ - cotransporter KCC2 renders GABA hyperpolarizing during neuronal maturation. Nature 1999; 397: 251-5.

Rivera C, Voipio J, Thomas-Crusells J, Li H, Emri Z, Sipila S, et al. Mechanism of activitydependent downregulation of the neuron-specific K-Cl cotransporter KCC2. J Neurosci 2004; 24: 4683-91.

Skold C, Levi R, Seiger A. Spasticity after traumatic spinal cord injury: nature, severity, and location. Arch Phys Med Rehabil 1999; 80: 1548-57.

Skup M, Ziemlinska E, Gajewska-Wozniak O, Platek R, Maciejewska A, Czarkowska-Bauch J. The impact of training and neurotrophins on functional recovery after complete spinal cord transection: cellular and molecular mechanisms contributing to motor improvement. Acta Neurobiol Exp (Wars) 2014; 74: 121-41.

Tan T, Watts SW, Davis RP. Drug Delivery: Enabling Technology for Drug Discovery and Development. iPRECIO Micro Infusion Pump: Programmable, Refillable, and Implantable. Front Pharmacol 2011; 2: 44.

Tashiro S, Shinozaki M, Mukaino M, Renault-Mihara F, Toyama Y, Liu M, et al. BDNF Induced by Treadmill Training Contributes to the Suppression of Spasticity and Allodynia After Spinal Cord Injury via Upregulation of KCC2. Neurorehabil Neural Repair 2015; 29 : 677-89.

Thompson FJ, Reier PJ, Lucas CC, Parmer R. Altered patterns of reflex excitability subsequent to contusion injury of the rat spinal cord. J Neurophysiol 1992; 68: 1473-86.

Weishaupt N, Blesch A, Fouad K. BDNF: the career of a multifaceted neurotrophin in spinal cord injury. Exp Neurol 2012; 238: 254-64.

Yates C, Charlesworth A, Allen SR, Reese NB, Skinner RD, Garcia-Rill E. The onset of hyperreflexia in the rat following complete spinal cord transection. Spinal Cord 2008; 46: 798-803.

Ying Z, Roy RR, Zhong H, Zdunowski S, Edgerton VR, Gomez-Pinilla F. BDNF-exercise interactions in the recovery of symmetrical stepping after a cervical hemisection in rats. Neuroscience 2008; 155: 1070-8.

Zadran S, Jourdi H, Rostamiani K, Qin Q, Bi X, Baudry M. Brain-derived neurotrophic factor and epidermal growth factor activate neuronal m-calpain via mitogen-activated protein kinase-dependent phosphorylation. J Neurosci 2010; 30: 1086-95.

Zhou HY, Chen SR, Byun HS, Chen H, Li L, Han HD, et al. N-methyl-D-aspartate receptor- and calpain-mediated proteolytic cleavage of $\mathrm{K}+-\mathrm{Cl}$ - cotransporter-2 impairs spinal chloride homeostasis in neuropathic pain. J Biol Chem 2012; 287: 33853-64. 


\section{LEGENDS}

Figure 1 Experimental timeline and programmable infusion pump delivery. A) The surgical procedure took place on day 1. During the procedure, a complete spinal cord injury was performed at the thoracic level (T12). An intrathecal catheter was also implanted subdurally and fitted to a programmable microinfusion pump (iPrecio(C) to deliver drugs to the lumbar enlargement of the spinal cord. During the post-SCI recovery period ( $\sim 4$ days), saline was continuously delivered at a steady flow rate $(3 \mu 1 /$ hour $)$ to prevent blockage of the tip of the cannula. The iPrecio ${ }^{(}$ Management system calculates the time at which the reservoir needs to be emptied from saline and re-filled with drugs so as to reach the tip of the cannula 30 minutes prior to the first rehabilitation session. The saline remaining in the reservoir was then replaced through the subcutaneous port with the vehicle (10\% DMSO in saline) for SCI controls, VU0240551 (30 $\mu \mathrm{M})$ or TrkB-IgG (10 $\mu \mathrm{g} / \mathrm{ml}$ in PBS). B) The pumps were programmed on a variable $24 \mathrm{~h}$ delivery schedule. Delivery started 30 minutes before the exercise session at a flow rate of $16 \mu \mathrm{l} / \mathrm{h}$ for 30 minutes followed by a $4 \mu \mathrm{l} / \mathrm{h}$ maintenance dose during the 60 minutes training session. Drug delivery was tapered off during the remaining 22.5 hours to $0.2 \mu \mathrm{l} / \mathrm{h}$, the lowest delivery flow to prevent clogging of the catheter.

Figure 2 Representative recordings of H-reflexes evoked by a train of stimulation to the tibial nerve in the interosseus muscle. A) The stimulation of the tibial nerve evokes a volley in Ia afferents (solid pink arrows) that monosynaptically excite alpha motoneurons. The M-wave (green arrow) precedes the H-reflex (dotted pink arrow) and is due to the direct activation of motor axons. B-E) Typical EMG recordings over a series of 20 stimulations to the tibial nerve illustrating that during a $10 \mathrm{~Hz}$ stimulation train, the depression of the H-reflex is impaired after SCI (B) but substantially restored in exercised animals (C). However, the exercised groups that received VU0240551 (D) or TrkB-IgG (E) during the daily rehabilitation session exhibited a very modest depression as compared to exercised animals. Overall, blocking KCC2 or BDNF activity in exercised animals (D-E) yields responses similar to non-exercised SCI (B). 
Figure 3 The activity-dependent recovery of the FDD in exercised animals is prevented by blocking KCC2 activity or scavenging BDNF after SCI. $\boldsymbol{A}$-D) Averaged H-reflex traces (n>15) evoked by the stimulation of the tibial nerve at $0.3 \mathrm{~Hz}$ (black), $5 \mathrm{~Hz}$ (dark grey), $10 \mathrm{~Hz}$ (light grey). Increasing stimulus frequency from $0.3 \mathrm{~Hz}$ to $10 \mathrm{~Hz}$ decreased $\mathrm{H}$-reflex amplitude in all animal groups. $\boldsymbol{E})$ There was a statistically significant difference across stimulation frequency $(\mathrm{p}<0.001)$ and across experimental groups $(\mathrm{p}<0.001)$ and the interaction between frequency and groups was also significant $(\mathrm{p}<0.001)$. H-reflexes were significantly smaller at $5 \mathrm{~Hz}$ and $10 \mathrm{~Hz}$ as compared to $0.3 \mathrm{~Hz}$ in all groups. The FDD drastically decreased after SCI (blue, see also A) with the amplitude of the H-reflex increasing from $13 \pm 3 \%$ in intact animals to $57 \pm 7 \%$ in SCI at $5 \mathrm{~Hz}(\mathrm{P}<0.001)$ and from $6 \pm 2 \%$ to $46 \pm 6 \%$ at $10 \mathrm{~Hz}(\mathrm{P}<0.001)$. Rehabilitation prevented this decrease with values not significantly different from uninjured animals at $5 \mathrm{~Hz}(24 \pm 2 \% ; \mathrm{P}=0.358)$ and $10 \mathrm{~Hz}(6 \pm 2 \%$; $\mathrm{P}=0.653$ )(green, see also B), but displayed considerably more depression than SCI at both stimulation frequencies $(\mathrm{P}<0.001)$. VU0240551 prevented the recovery of FDD (pink, see also C)

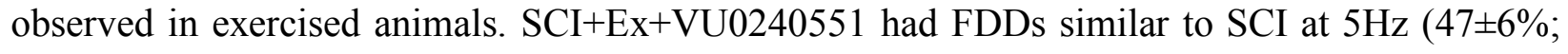
$\mathrm{P}=0.317)$ and $10 \mathrm{~Hz}(40 \pm 6 \% ; \mathrm{P}=0.650)$, but the depression was significantly lower than in exercised animals in which KCC2 activity was not blocked ( $\mathrm{P}=0.002$ and $\mathrm{P}<0.001$ respectively). Scavenging BDNF also prevented the activity-dependent recovery of the FDD (black, see also D) at $5 \mathrm{~Hz}$ and $10 \mathrm{~Hz}(\mathrm{P}<0.001)$ with values similar to sedentary $\mathrm{SCI}$ controls at $5 \mathrm{~Hz}(\mathrm{P}=0.951)$ and $10 \mathrm{~Hz}(\mathrm{P}=0.986)$ and $\mathrm{SCI}+\mathrm{Ex}+\mathrm{VU} 0240551(\mathrm{P}=0.309$ and $\mathrm{P}=0.778$, respectively $)$. Data is presented as mean \pm SEM expressed as a percentage of the response obtained at $0.3 \mathrm{~Hz}$. $* * * \mathrm{P}<0.001$. Twoway ANOVA analysis with Holm-Sidak post hoc test, $\mathrm{n}=9-11$ animals/group. F) The $\mathrm{H}_{\max } / \mathrm{M}_{\max }$ ratio, was also significantly different across groups $(\mathrm{P}<0.001)$. Post-hoc analysis revealed that SCI increases the $\mathrm{H}_{\max } / \mathrm{M}_{\max }$ ratio $(\mathrm{P}<0.027)$. Exercise restored $\mathrm{H}_{\max } / \mathrm{M}_{\max }$ which was lower than SCI values $(\mathrm{P}=0.045)$ but similar to intact $(\mathrm{P}=0.986)$. VU0240551 prevented the activity-dependent decrease in the $\mathrm{H}_{\max } / \mathrm{M}_{\max }$ which were not different from SCI $(\mathrm{P}=0.980)$ but significantly higher than exercised SCI $(\mathrm{P}=0.041)$ and intact $(\mathrm{P}=0.021)$. Scavenging BDNF also prevented the activitydependent decrease in the $\mathrm{H}_{\max } / \mathrm{M}_{\max }$ ratio $(\mathrm{P}=0.033)$ with values similar to SCI $(\mathrm{P}=0.974)$ and $\mathrm{SCI}+\mathrm{Ex}+\mathrm{VU} 0240551(\mathrm{P}=0.858)$. For illustration purposes, significance is illustrated for $10 \mathrm{~Hz}$ only. $\mathrm{H}_{\max } / \mathrm{M}_{\max }$ ratios are presented as mean $\pm \mathrm{SEM}$. ${ }^{*} \mathrm{P}<0.05$. One-way ANOVA analysis with Holm-Sidak post hoc test, $\mathrm{n}=9-11$ animals/group). 


\section{Figure 4 The activity-dependent modulation of KCC2, NKCC1 and BDNF protein} expression in the lumbar enlargement of SCI rats requires KCC2 and BDNF activity. Western blot analysis shows that A) One-way ANOVA confirmed differences in KCC2 protein expression across groups $(\mathrm{P}<0.001)$. Further post hoc analysis showed that KCC2 expression is modulated after SCI, decreasing to $64 \pm 3 \%$ of intact values $(\mathrm{P}=0.015)$. This decrease was prevented by a rehabilitation program whether KCC2 was blocked $(\mathrm{P}<0.034)$ or not $(\mathrm{P}<0.021)$ as both SCIEx and SCI+Ex+VU0240551 displayed KCC2 expression levels similar to intact $(93 \pm 7 \%$, $\mathrm{P}=0.898$ and $92 \pm 10 \%, \mathrm{P}=0.944$ respectively). Scavenging BDNF prevented the activitydependent increase in KCC2 expression with values similar to sedentary animals $(63 \pm 5 \%$, $\mathrm{P}=0.989)$, and lower than intact $(\mathrm{P}=0.015)$ and $\mathrm{SCI}+\mathrm{Ex}(\mathrm{P}=0.022)$. One-way ANOVA analysis $(\mathrm{P}<0.001)$ with Holm-Sidak post hoc test, $\mathrm{n}=6-11 /$ group). B) One-way ANOVA confirmed a difference in BDNF protein expression between groups $(\mathrm{P}<0.001)$. The decrease in BDNF expression after a chronic SCI as compared to intact $(\mathrm{P}=0.024)$ was prevented by exercise. SCIEx displayed BDNF expression levels higher than SCI $(\mathrm{P}<0.001)$ and similar to intact $(\mathrm{P}=0.425)$. Blocking KCC2 activity prevented the beneficial effect of exercise on BDNF levels with values significantly lower than exercised animals receiving the vehicle $(\mathrm{P}=0.011)$. Scavenging BDNF during training yielded lower levels of BDNF in the lumbar enlargement $(\mathrm{P}=0.043)$. C) NKCC1 protein expression in the lumbar enlargement was significantly different between groups $(\mathrm{P}=0.003)$. NKCC1 levels tended to increase after SCI. Although this increase did not reach statistical significance $(\mathrm{P}=0.068)$, rehabilitation returned $\mathrm{NKCC} 1$ expression levels close to intact (93 $\pm 4 \%, \mathrm{P}=0.964)$ with significantly less $\mathrm{NKCC} 1$ in the lumbar enlargement than sedentary SCI animals $(147 \pm 14 \%, \mathrm{P}=0.036)$. Blocking $\mathrm{KCC} 2$ prevented the activity-dependent decrease in NKCC1 expression and SCI+Ex+VU0240551 displayed values similar to sedentary SCI animals (161 $\pm 24 \%, \mathrm{P}=0.930)$ but higher than SCI-Ex $(\mathrm{P}=0.012)$. Scavenging BDNF did not prevent the activity-dependent decrease in NKCC1 expression $(97 \pm 16 \%, \mathrm{P}=0.969)$. One-way ANOVA analysis with Holm-Sidak post hoc test, $\mathrm{n}=6-11$ /group). One-way ANOVA analysis $(\mathrm{P}<0.001)$ with Holm-Sidak post hoc test, $\mathrm{n}=6-11$ /group). Protein levels are presented as mean $\pm \mathrm{SEM}$. * $\mathrm{P}<0.05, * * * \mathrm{P}<0.001$ vs intact. 
Figure 5 Relationship between the expression of NKCC1, KCC2 and BDNF in the lumbar spinal cord. A) A linear regression analysis showed that there is a significant positive relationship between BDNF and KCC2 expression level in the lumbar spinal cord $\left(\mathrm{P}<0.001, \mathrm{R}^{2}=0.480\right)$. SCI and $\mathrm{SCI}+\mathrm{Ex}+\mathrm{TrkB}-\mathrm{IgG}$ groups are clustered in the lower left quadrant with low expression levels of BDNF and $\mathrm{KCC} 2$ while intact and $\mathrm{SCI}+\mathrm{Ex}$ are grouped in the top right quadrant displaying higher levels of both proteins. B) A linear regression analysis illustrate a significant negative relationship between $\mathrm{NKCC} 1$ and $\mathrm{KCC} 2$ expression level in the lumbar spinal cord $(\mathrm{P}=0.006$, $\mathrm{R}^{2}=0.188$ ) with low levels of KCC2 expression associated to higher levels of NKCC1.

Figure 6 Blocking KCC2 or BDNF activity during exercise prevents the activity-dependent increase in KCC2 levels in lumbar motoneuronal membrane. A) Digital images showing KCC2 expression in the membrane around the motoneuronal soma (white arrows) and also in dendrites in the ventral horn of the lumbar enlargement. B) Quantification of the integrated density of $\mathrm{KCC} 2$ around the motoneuronal membrane reveals that exercise increases KCC2 immunoreactivity around the membrane $(\mathrm{P}<0.001)$ and that blocking KCC2 or BDNF activity prevents this activity-dependent increase after SCI $(\mathrm{P}<0.001)$. Data are presented as means \pm SEM. Kruskal-Wallis ANOVA on ranks $(\mathrm{p}<0.001)$ followed by Dunn's method, $\mathrm{n}=5-8$ animals per group. $* * * \mathrm{P}<0.001$, Scale bar $=25 \mu \mathrm{m}$. 
bioRxiv preprint doi: https://doi.org/10.1101/489740; this version posted December 7, 2018. The copyright holder for this preprint (which was not certified by peer review) is the author/funder, who has granted bioRxiv a license to display the preprint in perpetuity. It is made available under aCC-BY 4.0 International license.

A

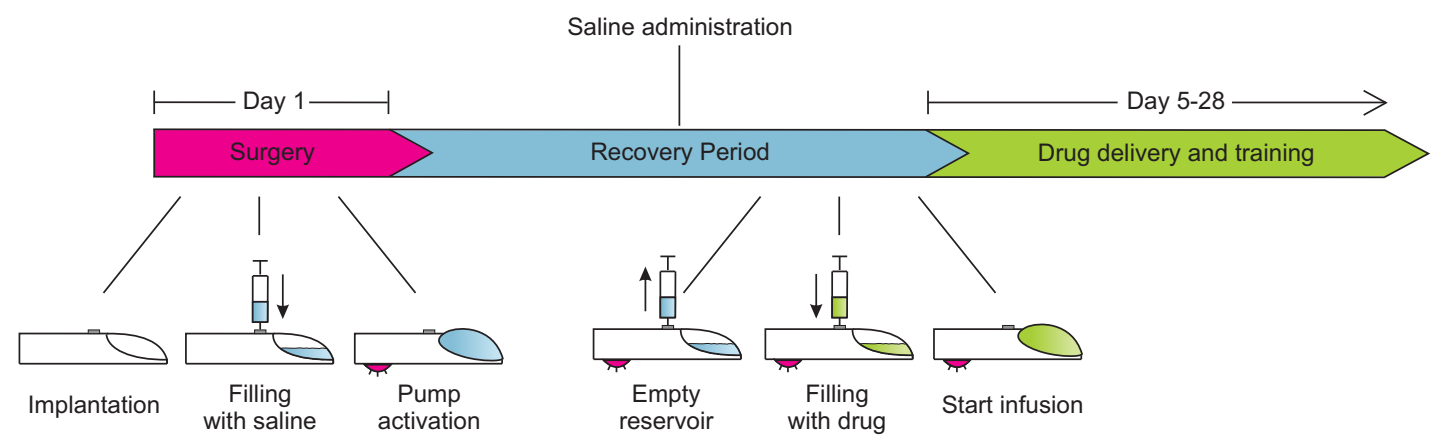

B

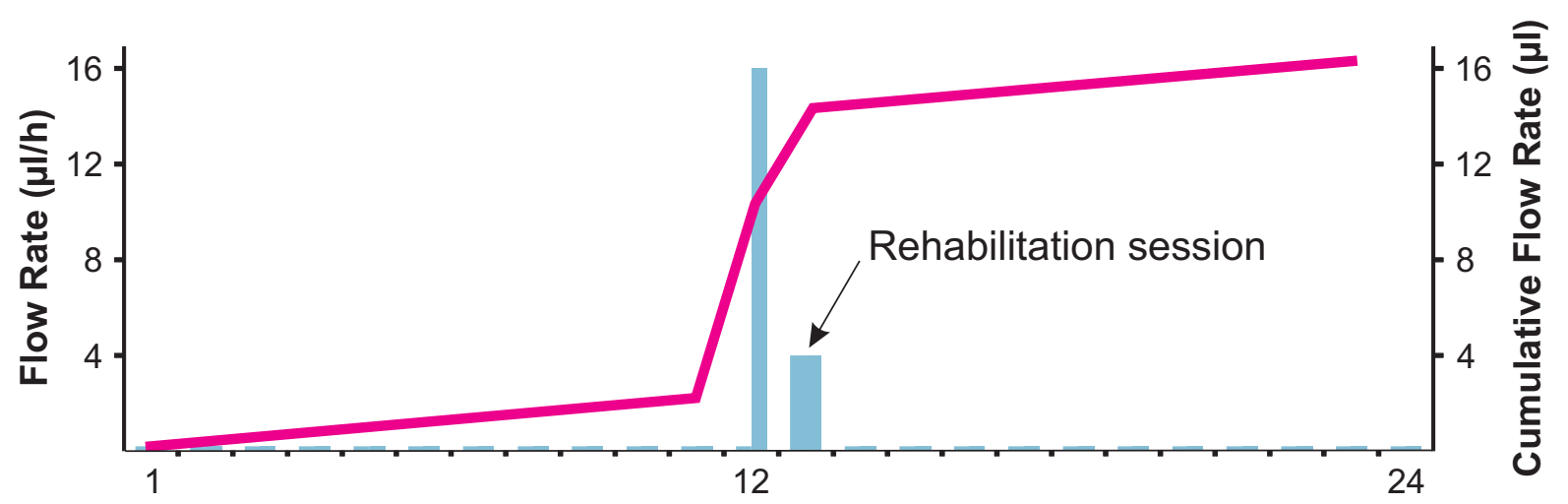

Hours 
bioRxiv preprint doi: https://doi org/10.1101/489740; this version posted December 7, 2018. The copyright holder for this preprint (which was not certified by peer review) is the author/funder, who has granted bioRxiv a license to display the preprint in perpetuity. It is made available under aCC-BY 4.0 International license.

A

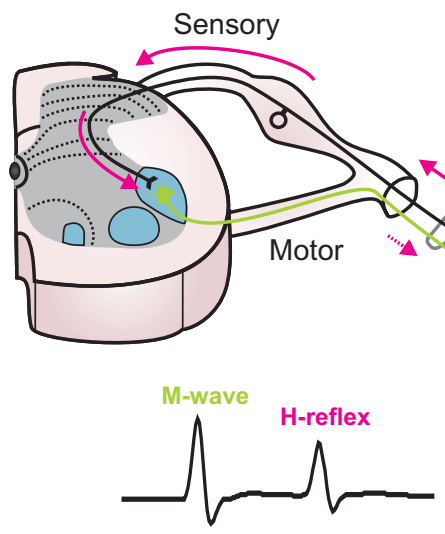

B

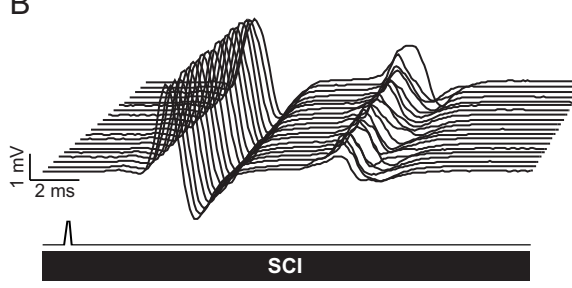

SCI

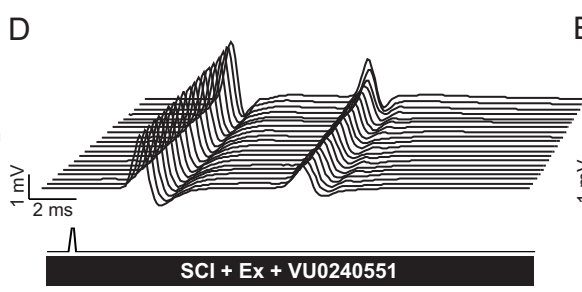

C

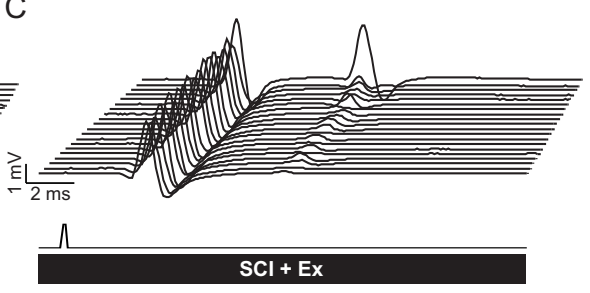

E

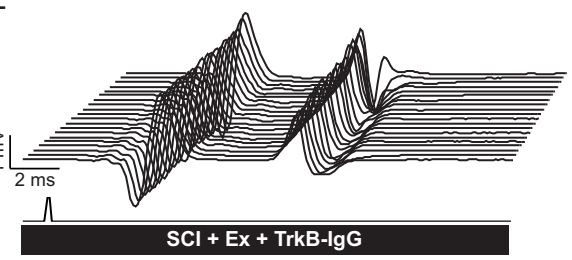


bioRxiv preprint doi: https://doi.org/10.1101/489740; this version posted December 7, 2018. The copyright holder for this preprint (which was

A not certified by peer review) is the author/funder, who has granted bioRxiv a license to display the preprint in perpetuity. It is made available

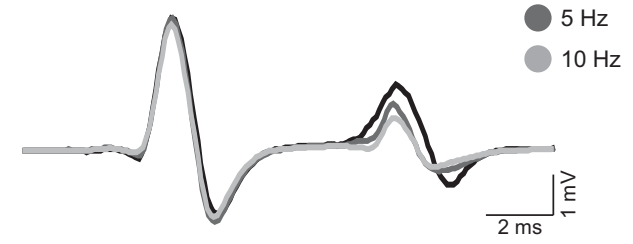

$\Lambda$

SCI

B

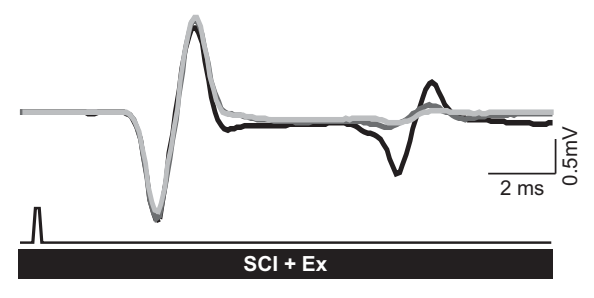

C

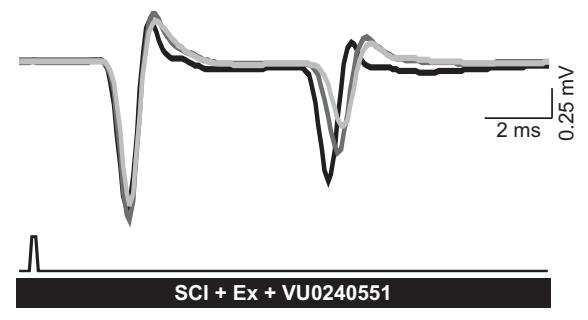

D

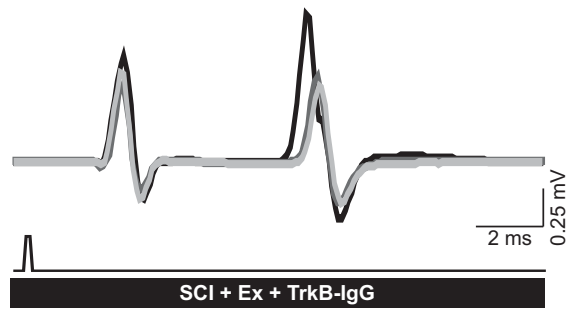
under 5 CC-BY 4.0 International license.

Frequency-dependent depression

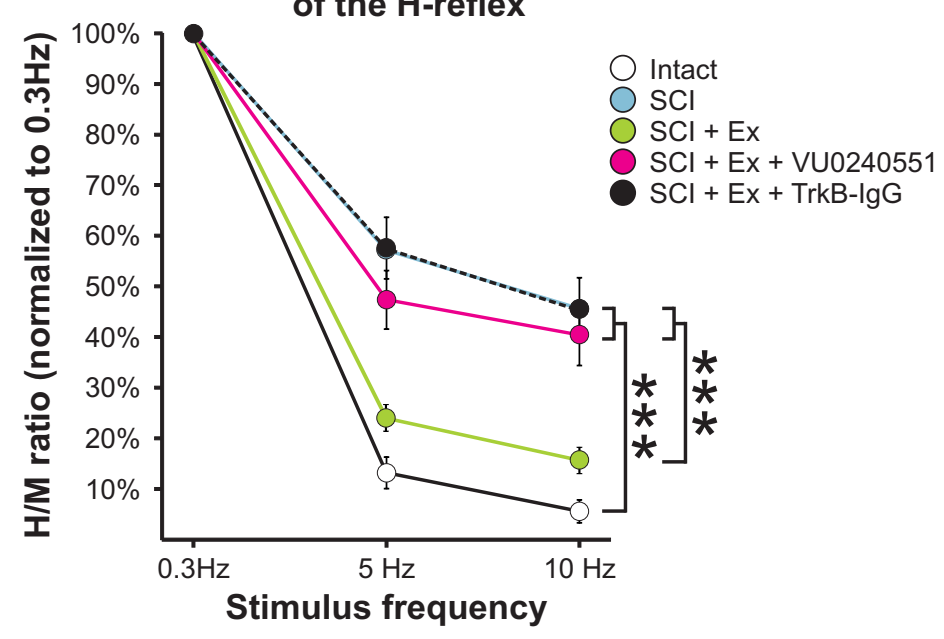

F

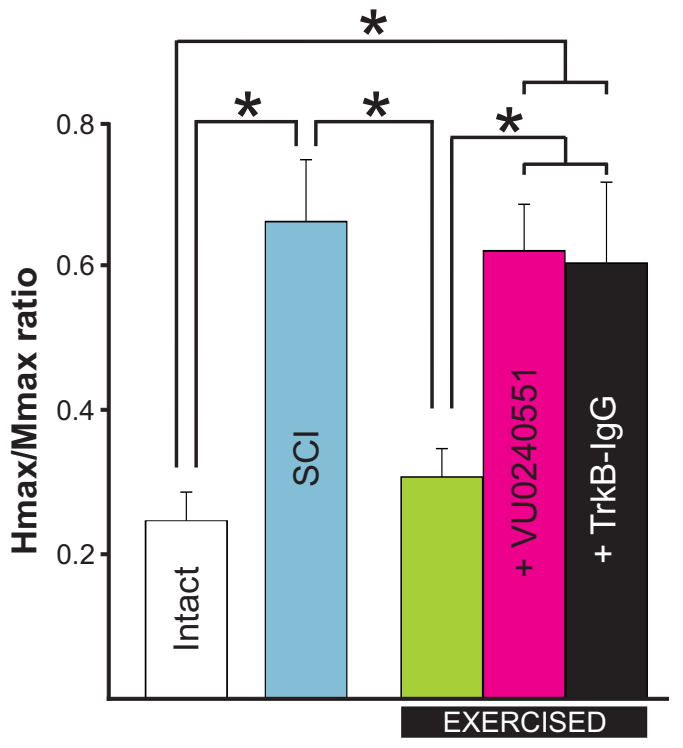


bioRxiv preprint doi: https://doi.org/10.1101/489740; this version posted December 7, 2018. The copyright holder for this preprint (which was not certified by peer review) is the author/funder, who has granted bioRxiv a license to display the preprint in perpetuity. It is made available under ACC-BY 4.0 International license.

A

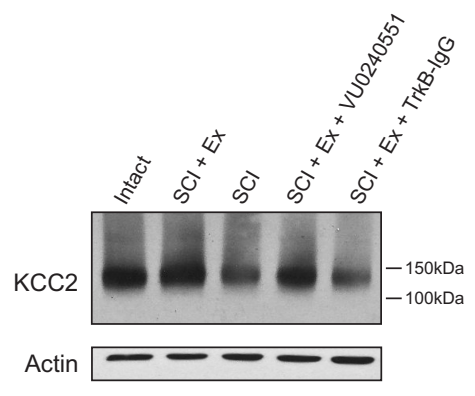

B

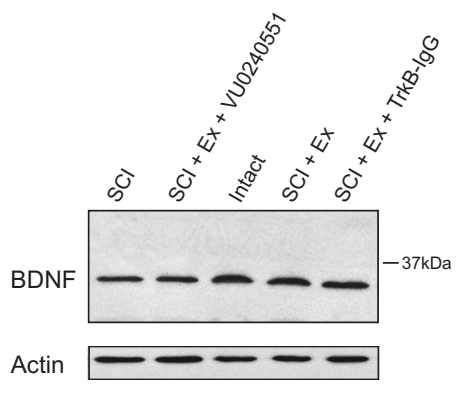

C

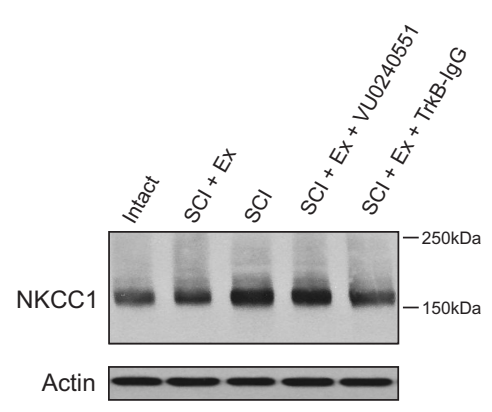

$\mathrm{KCC} 2$ protein

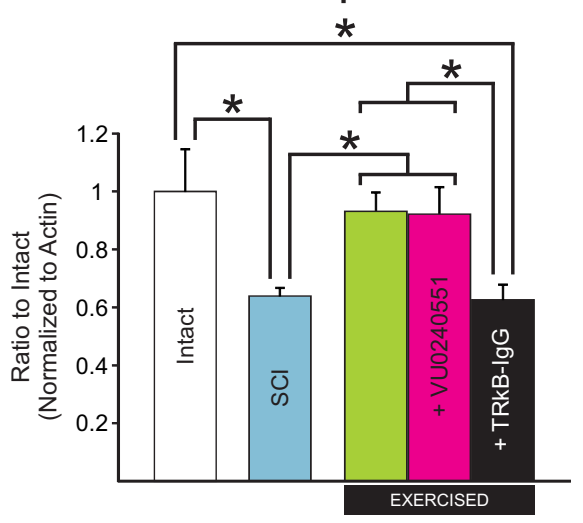

BDNF protein

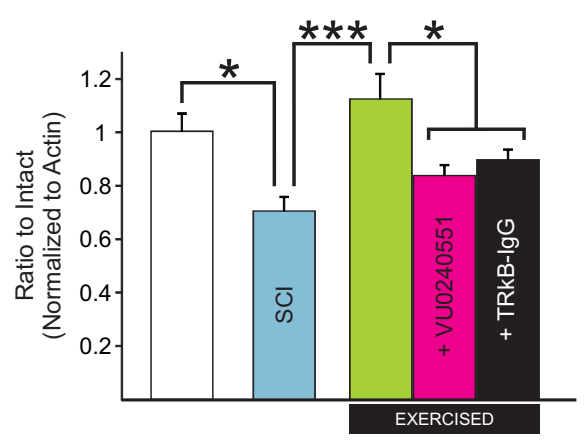

NKCC1 protein

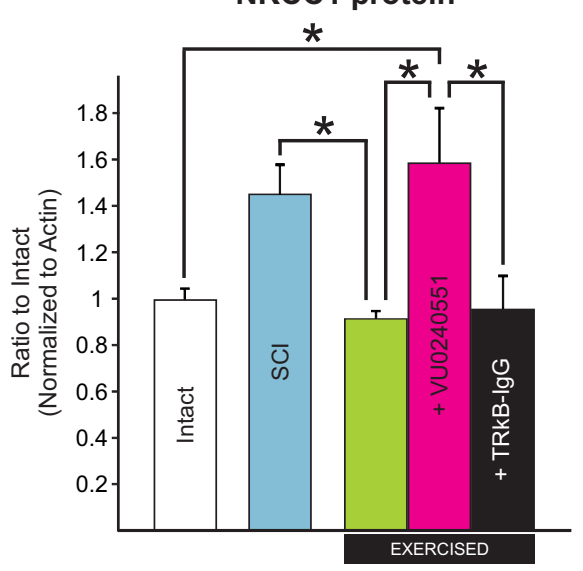


bioRxiv preprint doi: https://doi.org/10.1101/489740; this version posted December 7, 2018. The copyright holder for this preprint (which was not certified by peer review) is the author/funder, who has granted bioRxiv a license to display the preprint in perpetuity. It is made available under aCC-BY 4.0 International license.

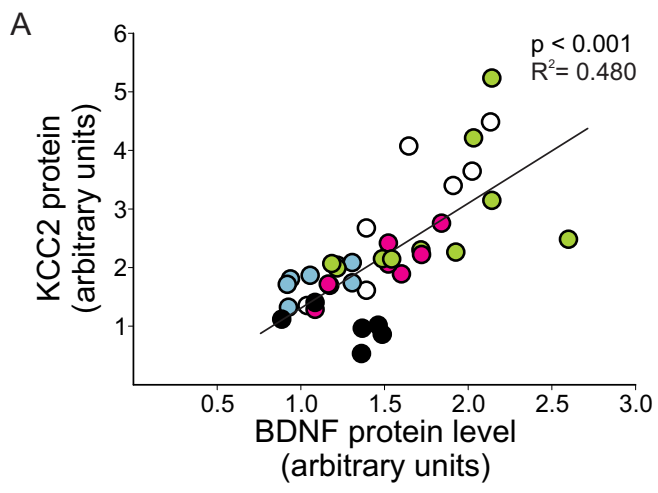

B

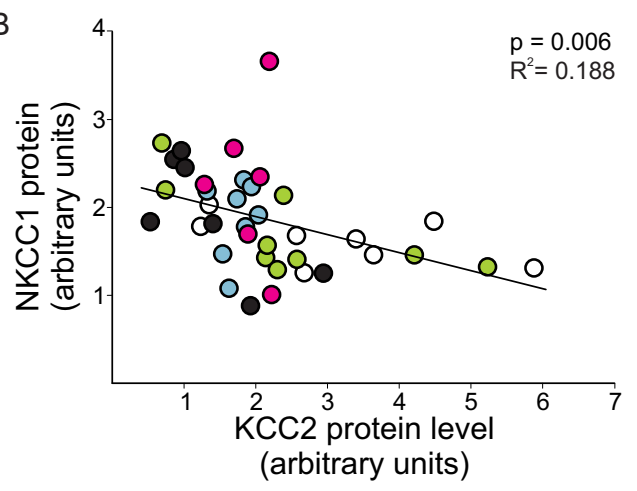


bioRxiv preprint doi: https://doi.org/10.1101/489740; this version posted December 7, 2018. The copyright holder for this preprint (which was not certified by peer review) is the author/funder, who has granted bioRxiv a license to display the preprint in perpetuity. It is made available under aCC-BY 4.0 International license.
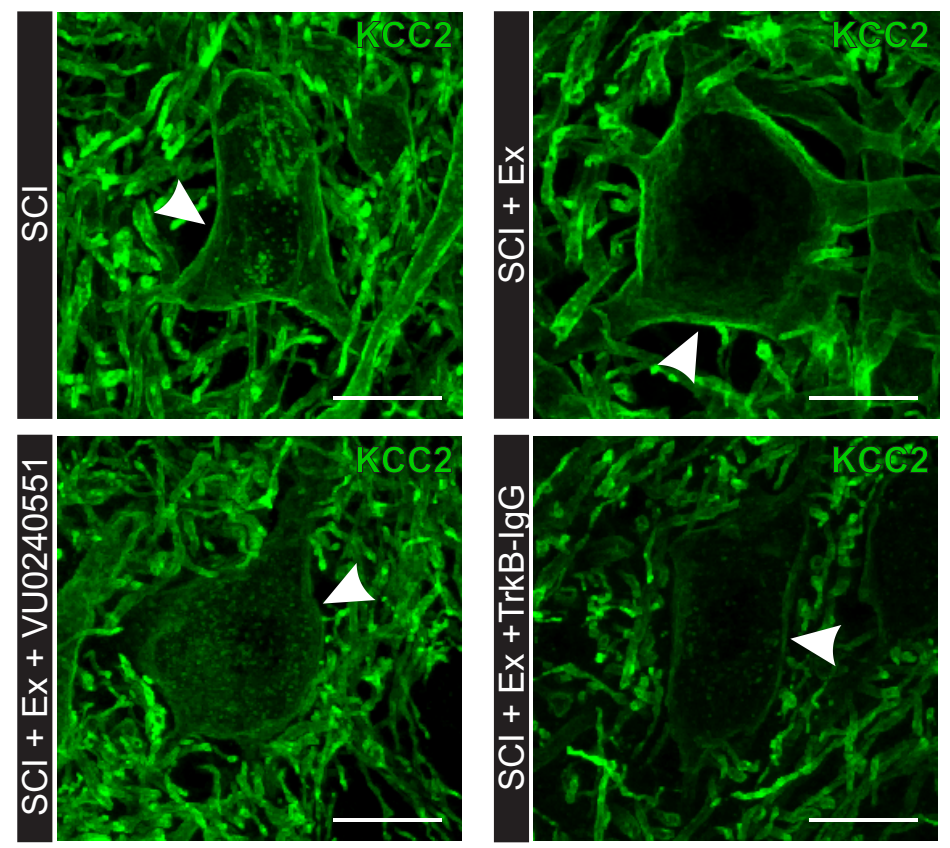

\section{Membrane}

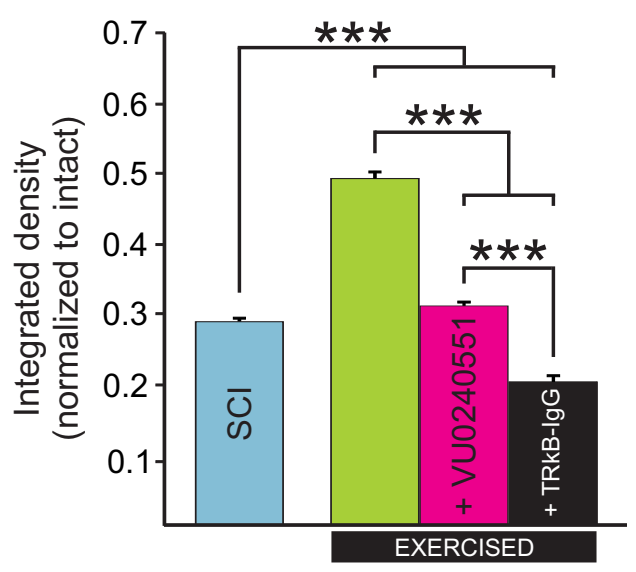


bioRxiv preprint doi: https://doi.org/10.1101/489740; this version posted December 7, 2018. The copyright holder for this preprint (which was not certified by peer review) is the author/funder, who has granted bioRxiv a license to display the preprint in perpetuity. It is made available under aCC-BY 4.0 International license.

Table 1. Properties of the M-Wave and H-Reflex: Latency, Amplitude, and Threshold

\begin{tabular}{|c|c|c|c|c|c|c|c|c|}
\hline & $\mathrm{n}=$ & $\begin{array}{l}\text { Motor threshold } \\
(\mathrm{mA})\end{array}$ & $\begin{array}{l}\mathrm{M}_{\max } \\
(\mathrm{mV})\end{array}$ & $\begin{array}{l}\mathrm{H}_{\max } \\
(\mathrm{mV})\end{array}$ & $\begin{array}{l}\text { M latency } \\
(\mathrm{ms})\end{array}$ & $\begin{array}{l}\text { H latency } \\
\text { (msec) }\end{array}$ & $\begin{array}{l}\text { H-reflex threshold } \\
\text { (x MT) }\end{array}$ & $\begin{array}{l}\mathrm{H}_{\max } \\
(\mathrm{xMT})\end{array}$ \\
\hline Intact & 11 & $0.013 \pm 0.003$ & $9.71 \pm 1.40$ & $3.38 \pm 0.78$ & $2.46 \pm 0.11$ & $9.35 \pm 0.50$ & $1.76 \pm 0.19$ & $1.76 \pm 0.19$ \\
\hline $\mathrm{SCl}$ & 11 & $0.019 \pm 0.002$ & $6.79 \pm 0.53$ & $2.71 \pm 0.34$ & $2.38 \pm 0.08$ & $8.84 \pm 0.18$ & $0.94 \pm 0.02^{\star \star *}$ & $1.38 \pm 0.13$ \\
\hline $\mathrm{SCl}+\mathrm{Ex}$ & 9 & $0.017 \pm 0.002$ & $5.22 \pm 0.57$ & $2.29 \pm 0.34$ & $2.19 \pm 0.08$ & $8.80 \pm 0.16$ & $1.09 \pm 0.05$ & $1.49 \pm 0.08$ \\
\hline SCI + VU0240551 & 8 & $0.019 \pm 0.004$ & $7.77 \pm 1.33$ & $2.59 \pm 0.68$ & $2.22 \pm 0.08$ & $8.65 \pm 0.19$ & $1.11 \pm 0.11^{*}$ & $1.58 \pm 0.08$ \\
\hline$S C I+E x+V U 0240551$ & 13 & $0.019 \pm 0.003$ & $7.64 \pm 0.99$ & $3.96 \pm 0.65$ & $2.50 \pm 0.09$ & $8.69 \pm 0.18$ & $1.10 \pm 0.04^{*}$ & $1.37 \pm 0.08$ \\
\hline $\mathrm{SCl}+$ TrkBlgG & 9 & $0.018 \pm 0.003$ & $6.77 \pm 0.58$ & $2.13 \pm 0.31$ & $2.49 \pm 0.06$ & $8.95 \pm 0.13$ & $1.05 \pm 0.05^{*}$ & $1.52 \pm 0.08$ \\
\hline $\mathrm{SCl}+\mathrm{Ex}+$ TrkBlgG & 11 & $0.024 \pm 0.005$ & $6.59 \pm 1.25$ & $3.35 \pm 0.75$ & $2.37 \pm 0.08$ & $8.84 \pm 0.17$ & $0.99 \pm 0.04^{\star *}$ & $1.42 \pm 0.18$ \\
\hline
\end{tabular}

Values are mean \pm SEM. MT, motor threshold. ${ }^{* *} \mathrm{P}<0.001,{ }^{* *} \mathrm{P}<0.01,{ }^{*} \mathrm{P}<0.05$ vs. intact. 